What are Agile, Flexible, or Adaptable Employees and Students? A Typology of Dynamic Individual Differences in Applied Settings

\author{
Jonas W. B. Lang ${ }^{12}$ \\ J. Malte Runge ${ }^{1}$ \\ Filip De Fruyt ${ }^{1}$ \\ ${ }^{1}$ Ghent University \\ ${ }^{2}$ Business School, University of Exeter
}

in press, European Journal of Personality

\begin{abstract}
Author Note
Jonas W. B. Lang https://orcid.org/0000-0003-1115-3443

J. Malte Runge http://orcid.org/0000-0003-0594-6578

Filip De Fruyt http://orcid.org/0000-0002-5552-0754

Correspondence concerning this article should be addressed to Jonas W. B. Lang, Faculty of Psychology and Educational Sciences, Henri Dunantlaan 2,9000 Ghent. Email: Jonas.Lang@ugent.be. We thank Sander Van Hoeck for helpful comments on an earlier version of this manuscript.
\end{abstract}




\begin{abstract}
The applied psychology literature has discussed and used a variety of different definitions of dynamic individual differences. Descriptions like dynamic, agile, adaptive, or flexible can refer to a variety of different types of constructs. The present article contributes to the literature by presenting an organizing typology of dynamic constructs. We also conducted a literature review of four major applied journals over the last 15 years to validate the taxonomy and to use it to map what type of dynamic individual differences constructs are typically studied in the applied psychology literature. The typology includes six basic conceptualizations of dynamic individual differences: Variability constructs (inconsistency across situations), skill acquisition constructs (learning new skills), transition constructs (avoiding "loss" in performance after unforeseen change), reacquisition constructs (relearning after change), acceleration/deceleration constructs (losing or gaining energy by displaying the behavior), and integration/dissolution constructs (behavior becomes more or less uniform). We provide both verbal and statistical definitions for each of these constructs, and demonstrate how these conceptualizations can be operationalized in assessment and criterion measurement using $\mathrm{R}$ code and simulated data. We also show how researchers can test different dynamic explanations using likelihood-based $R^{2}$ statistics.
\end{abstract}




\section{What are Agile, Flexible, or Adaptable Students and Employees? A Typology of Dynamic Individual Differences in Applied Settings}

Work psychologists, economists, and educational researchers have argued that the rapid emergence of new technologies is changing the fundamental nature of work and education (World Bank, 2019). Modern work environments require employees and organizations to quickly react to changes. This increasingly volatile nature of modern education and work environments has recently led to a considerable interest in studying dynamic elements in both assessment and outcome measurement. In particular, applied researchers and practitioners have shown interest in measuring individual differences in dynamic predictor constructs such as dynamic skill acquisition or flexible personality traits in assessment. Furthermore, there is also considerable interest into studying individual differences in dynamic aspects of outcomes such as job performance or educational achievement (Abrahams et al., 2019; DeRue et al., 2012; Jundt et al., 2015).

The term dynamic originates from the Greek word dynamikos which means "powerful" and the contemporary use of the word is typically inspired by its use in physics to describe constant change (Merriam-Webster, 2019). Thus, dynamic refers to change processes over time. Dynamic effects can be alike across individuals, such as a normative developmental pattern that all individuals in a population demonstrate. Individual differences in dynamic effects refer to individual differences between individuals in the amount that change processes occur over time. These individual differences are typically continuous and approximately normally distributed. Such differences can be individual differences in the dynamics of assessment constructs (e.g. a personality trait/state) or individual differences in the dynamics of outcome measurements (e.g. job performance). In assessment, a broad range of different methods can be used to capture dynamic individual differences like using Likert-scales

(e.g., Fleeson \& Gallagher, 2009; Lang, Lievens, et al., 2019), ambulatory assessment methods (Abrahams et al., 2019) or situational judgement tests (e.g., Lievens et al., 2018). Individual differences 
in the dynamics of outcome measurements are typically captured by extracting information from multiple performance measurements over shorter or longer periods of time (Bliese et al., 2017; Farrell \& McDaniel, 2001).

Studying individual differences in dynamic constructs (either in assessment or in outcome measurement) in applied settings usually presents researchers with a number of challenges. A first challenge is defining the exact nature of the kind of dynamics that the researcher seeks to study. The literature, so far, has discussed a variety of different conceptualizations of change and dynamics, often from the perspective of particular science domains, such as personality psychology, motivational psychology, psychometrics, biology or econometrics. Moreover, very different terms like agile, adaptive, flexible, or learning have been used to refer to these different types of dynamic phenomena (DeRue et al., 2012; Jundt et al., 2015; Lang \& Bliese, 2009). A second challenge is that most of these definitions of individual differences in dynamics and their associated labels are usually not closely tied to a psychometric model describing the key parameters of the individual dynamic process. This is crucial to advance and streamline research and facilitate comparison of research findings. A final and third challenge, is that this lack of clarity in the psychometric specification of the type of individual differences' dynamics, hampers the development of a design and the choice for adequate measures to assess the type of individual differences' dynamics.

The current review paper tries to tackle these challenges, by (a) providing a first integrative taxonomy outlining and accommodating the most frequently used conceptualizations of individual differences in dynamics studied in applied psychology settings, (b) specifying the accompanying psychometric and measurement models describing all key parameters and their relationships, (c) providing the syntax or codes and suggestions to analyze such data, (d) running simulations to illustrate the types of dynamics that are included in the taxonomy, and finally, (e) list a number of examples from the broader psychological literature that either describe dynamic individual differences at the predictor 
side or at the level of the outcome criteria or both.

The aspired taxonomy is not meant to be an exhaustive taxonomy covering all individual differences in dynamics studied across various scientific fields, but aims to provide a comprehensiveenough account of dynamics that will help researchers to better articulate and specify their research questions, designs and choice of measures. We will build such taxonomy, starting from the perspective of multilevel mixed-effects models to distinguish among various individual differences' dynamics conceptualizations. We will conduct a literature review of the organizational and educational psychology field and classify its results in this emerging taxonomy.

The goal of the present article is to build on existing work on dynamic phenomena and also on methodological work outside applied disciplines like work and organizational psychology or educational psychology, and address some of the challenges in studying dynamic constructs in assessment and in outcome measurement. We specifically aim to contribute to the literature by developing and presenting an organizing typology of dynamic constructs, that can be conveniently used and applied for predictor and outcome measurement in applied settings. We therefore developed a typology that is not based solely on verbal descriptions but also includes prototypical psychometric/measurement models. These psychometric models can be fitted to empirical data but can also be used to simulate data to study power or to examine the plausibility of theoretical model assumptions using simulated data (e.g., Vancouver et al., 2010). We specifically show how researchers can test different dynamic explanations for dynamic processes in either assessment or outcome measurement data.

\section{Individual Differences in Dynamics}

Individual differences research and related fields like personality psychology are sometimes seen as research domains that primarily focus on individual differences in stable behavior (e.g., Mischel, 1968; Pervin, 1994), i.e. they describe differences between individuals in mean levels of a trait typically indicated by the average score on a set of personality descriptive items. However, individual differences 
researchers are also frequently interested in within-person variability of behavior related to the same trait, in other words studying its dynamic nature within the person (Atkinson \& Birch, 1970; Carver \& Scheier, 1998; Rauthmann et al., 2019; Verhelst \& Glas, 1993). The study of individual differences in dynamics also has a long tradition (Flügel, 1929; Kehr, 1916; Spearman \& Jones, 1950; Stern, 1911; Walton, 1936). For instance, William Stern discussed individual differences in intra-individual variability in persons already at the beginning of the last century (Stern, 1911). Other early personality researchers built on this work on variability, and discussed within-person differences in variability as an individual difference construct itself, using labels like oscillation (Flügel, 1929) and steadiness of character (Walton, 1936).

Such dynamic differences can take differen forms. For example, in addition to mean-level differences between individuals, we can also study variability in conscientiousness within the person, as it relates to momentary task performance (Debusscher et al., 2016) or in response to various work demands. Likewise, individual differences in the dynamics of neuroticism can be described in response to trauma. A researcher may also try to investigate a construct he or she labels "agility" by assessing how quickly individuals make the right decision in various situations they are confronted with, relative to their average situational judgement ability across these situations. These examples illustrate that, beyond a certain average on an individual difference construct, there is also variability in people's reaction, so we have to deal with a more stable but also a dynamic counterpart. A critical test of the notion that a dynamic perspective adds meaningful new insights is whether it explains variance on top of this stable counterpart in a criterion or in the responses of a statistical model of behavior data.

\section{Dynamic Assessment vs. Dynamic Criteria}

In applied fields, dynamic individual differences can potentially be useful in two different contexts: In dynamic assessment and in dynamic criterion measurement. In dynamic assessment, the dynamic construct targets a form of change within a construct. Frequently, the idea is that the 
constructs as operationalized in a measure captures a generalizable tendency of respondents (dynamic individual difference constructs) that is useful for predicting important criteria. Dynamic constructs can in principle be extracted from a variety of measures used in assessment like Likert-scale personality inventories, situational judgement tests, assessment centers, or mini assessment centers, or also more general psychological measures like ability tests or objective personality measures.

In dynamic criterion constructs, the notion of dynamic individual differences is applied to the criterion side to measure individual differences in outcome criteria. For instance, an organization or a researcher may be interested in predicting agile behavior within a work environment like an air-traffic controlling task (Niessen \& Jimmieson, 2016), individual differences in learning on the job, or employees' ability to cope with rapid organizational change. It may seem like a logical step in many cases to match individual differences in dynamics of assessment constructs with dynamic criteria. However, this is not always the case and we will show in our literature review later in this paper that most studies in the literature focus on either dynamic assessment or dynamic criteria.

\section{Dynamic Phenomena and Individual Differences in Dynamics}

One challenging aspect of dynamic phenomena is that not all forms of dynamics reflect individual differences in dynamics (Bolker, 2008; Carver \& Scheier, 1998; Keele \& Kelly, 2006; Lang, 2014; Verhelst \& Glas, 1993). The reason is that dynamic phenomena can uniformly occur across an entire sample, hence demonstrating no individual differences. It is thus important for researchers to conceptually separate normative dynamics (i.e. those that apply to the whole sample) from dynamic individual differences (i.e. individual differences in change). When an effect applies to the sample as a whole, we refer to these effects as 'normative' effects, because the same patterns are on average followed by all individuals. However, the degree to which such normative patterns may be observed, may show individual differences, for example, employees becoming more agreeable with increasing age (the normative pattern), though this increase is less pronounced for those working in enterprising 
occupations (Wille \& De Fruyt, 2014).

A popular approach for understanding dynamic phenomena is the use of statistical or psychometric models (Borsboom, 2006; Mitchell et al., 2017; Tal, 2017). The advantage of statistical dynamic models is that models make assumptions about a dynamic process explicit and testable, and also allow researchers to uncover dynamic phenomena from seemingly complex data. In the context of dynamic models, individual differences in dynamics can typically be viewed as latent variables in the language of the psychometric literature, or random effect in the language of the multilevel literature. Latent variables/random effects are typically assumed to be normally distributed. While individual differences do not necessarily need to be normally distributed, adding the normal distribution assumption allows researchers to use more simple psychometric models.

A simple example that illustrates the distinction between normative dynamics and individual differences in dynamics, and also the use of models to understand both types of phenomena is a simple growth model. For instance, consider a growth model predicting reading motivation during adolescence for students $\mathrm{j}$ across measurements $\mathrm{i}$. The model includes a common intercept $\mathrm{\gamma}_{00}$, an average effect of TIME, $\gamma_{10}$, a residual error for each measurement $e_{\mathrm{ij}}$, and finally an individual-difference variable capturing individual differences in the overall level of reading motivation, $u_{0 j}$. This model can be written using the formula $Y_{\mathrm{ij}}=\left(\gamma_{00}+u_{0 \mathrm{j}}\right)+\nu_{10} T I M E_{\mathrm{i}}+e_{\mathrm{ij}}$. A more elaborate way to write the model that is frequently used in the literature (Bryk \& Raudenbush, 1987; Singer \& Willett, 2003) is to separate the model into a Level 1 equation, $Y_{\mathrm{ij}}=\pi_{0 \mathrm{j}}+\pi_{1 \mathrm{j}} T I M E_{\mathrm{i}}+e_{\mathrm{ij}}$, and two Level 2 equations, $\pi_{0 \mathrm{j}}=\gamma_{00}+u_{0 \mathrm{j}}$, and $\pi_{1 \mathrm{j}}=$ $Y_{10}$

When the effect of time, $\gamma_{10}$, is positive and substantial, this effect can be seen as an overall increase in reading motivation during early adolescence and this effect is dynamic in the sense that it captures constant change. However, this effect is not an individual differences' effect in dynamics. In addition to the normative change effect, individual differences in dynamics can be added to the model 
by adding the effect $u_{1 \mathrm{j}}$ to the model, $Y_{\mathrm{ij}}=\left(\gamma_{00}+u_{0 \mathrm{j}}\right)+\left(\gamma_{10}+u_{1 \mathrm{j}}\right) T I M E_{\mathrm{i}}+e_{\mathrm{ij}} \cdot u_{1 \mathrm{j}}$ is an individual difference effect in the slope that captures how fast students improve in their reading motivation, hence reflecting variation in the steepness of the slope. This individual difference construct can be used to predict stable criteria in the future, or alternatively, a dynamic criterion (e.g., degree attainment).

\section{Development of the Typology}

Recent research on affect dynamics has noted that a proliferation of dynamic individual difference conceptualizations may have limited scientific advancement on understanding the link between affect dynamics and well-being (Dejonckheere et al., 2019; Wendt et al., 2020). A potential reason is that various dynamic measures of affect are redundant and mathematically interdependent (Jahng et al., 2008; Mestdagh et al., 2018). We therefore believe that verbal definitions of different types of constructs are typically limited scientifically because it is hard to reach a scientific consensus on the basis of verbal descriptions. Accordingly, the literature on dynamic constructs has not come to a clear consensus on the basis of verbal descriptions like agile, adaptive, flexible, or learning ability. Some improvements in scientific communication can possibly be reached by providing a typology. In the present paper, our goal was therefore not only to develop such a typology but also to base the typology on statistical definitions on how the phenomenon could be modeled. In developing the typology, we built on the multilevel mixed-effects modeling framework. The advantage of using this framework is that it is closely related to most statistical methods in individual differences research. To ensure that the typology would cover a broad range of phenomena, we searched for prototypical examples of dynamic constructs in the work and organizational psychology literature (e.g., Ackerman, 1992; Lievens et al., 2018; Niessen \& Lang, 2020; Ployhart \& Bliese, 2006), the methodological and statistical literature (e.g., Bliese \& Lang, 2016; Bliese \& Ployhart, 2002; Bolker, 2008; Ployhart \& Vandenberg, 2010; Raudenbush, 1988; Singer \& Willett, 2003), the educational (e.g., Connor et al., 2014; Y. S. Kim et al., 2010; Ryan \& Shim, 2012) as well as the personality literature (e.g., Carver \& Scheier, 1998; Fleeson \& Jayawickreme, 
2015; Lang, Lievens, et al., 2019; Rauthmann et al., 2019; Sosnowska, Kuppens, et al., 2019) and placed these constructs into the framework of multilevel mixed-effects models. From this exercise, it became clear that the dynamic individual difference constructs we found could all be described in terms of six major categories that correspond to a model component of the multilevel mixed-effects model. We did not come across a fundamentally different operationalization of dynamic individual differences and consequently the six identified categories constituted the elements of the typology: (1) Variability constructs (individual differences in inconsistency across situations), (2) skill acquisition constructs (individual differences in learning new skills), (3) transition constructs (individual differences in avoiding "loss" after unforeseen change), (4) reacquisition constructs (individual differences in relearning after change), (5) acceleration/deceleration constructs (individual differences in gaining or losing behavioral energy by displaying the behavior), and (6) dissolution/integration constructs (individual differences in the degree to which behavior becomes more or less uniform across time).

\section{Overview of the Typology and Examples}

After developing the typology, our next goal was to present detail on each of the categories in the typology. We provide both descriptions (verbal definitions) and typical statistical model specifications (statistical definitions) of each of the six dynamic individual differences in the typology, and discuss how these dynamic individual differences can be operationalized in assessment using psychometric methods. We therefore describe example models, we provide code to simulate dynamic data on the basis of each conceptualization of dynamic individual differences in the typology, visualize example datasets generated using this code, and fit the models to the example datasets. We also describe examples of how the conceptualizations have been operationalized and measured in published articles from the journals we reviewed in the literature study below. Table 1 provides an overview of the typology with additional detail.

All material, simulated data, and scripts written in $\mathrm{R}$ are available through the OSF 
(https://osf.io/x827q/?view_only=173fe10712ac48bab3c44b9fd18fbf24) so that researchers can use our $\mathrm{R}$ code and apply it to their own data. For fitting the models, we mainly utilized the $\mathrm{R}$ package nlme (Pinheiro et al., 2017; Pinheiro \& Bates, 2000). However, we also ran analyses using the package brms (Bürkner, 2017; Lester et al., 2019). brms is convenient because it uses a more modern approach for model specification (Bates et al., 2015) and can fit some models that nlme cannot fit as conveniently. The package uses Bayesian model estimation. The simulations are based on a function with the name simdy that we wrote for the purpose of this paper.

\section{Variability Constructs (Inconsistency Across Situations)}

Variability constructs capture individual differences in consistency across time. While publications on variability constructs date back as far as Stern's 1911 book and studies in the first half of the $20^{\text {th }}$ century, the approach is today most strongly associated with whole trait theory (Fleeson \& Jayawickreme, 2015). Whole trait theory defines traits as frequency distributions of typical behaviors. Consequently, whole trait theory describes personality using the average of personality states and the variability of these personality states with both representing important individual differences (Finnigan \& Vazire, 2018). These ideas have recently also been applied beyond personality research in other research areas like assessment using situational judgement tests (Lievens et al., 2018).

A key theoretical motivation for assuming the existence of variability constructs is research on person-situation interactions. A popular framework in this context is the cognitive-affective system theory of personality (Mischel \& Shoda, 1995). This model assumes inconsistency across situations as a result of past experiences of individuals with specific situations. For instance, one person may have learned to activate his/her conscientiousness in a specific situation while another person uses other personality states in the same situation. The result is a person-specific activation pattern of specific situation-trait or "if-then" links. The simulation demonstration in the appendix in the Mischel-Shoda (Mischel \& Shoda, 1995) article illustrates that an activation pattern in line with the CAPS theory will 
typically lead to systematic variability across situations within a trait domain. In theory, it could be possible from the perspective of CAPS theory to conduct more fine-grained analyses of individual trait activation patterns that underly individual differences in variability. However, this would require knowledge of each persons' specific 'if-then' links which in practice can rarely be obtained.

A simple statistical model for studying dynamic variability constructs is to simply use the standard deviation across multiple comparable measurements from, for instance, a diary or an experience sampling study. A slight extension of this concept that has the advantage that it can also control for time trends and allows researchers to more conveniently simulate data is the use of multilevel mixed-effects models with a heterogenous variance regression (see Table 1). This model extends the simple growth model discussed earlier (Level 1: $Y_{\mathrm{ij}}=\pi_{0 \mathrm{j}}+\pi_{1 \mathrm{j}} T I M E_{\mathrm{i}}+e_{\mathrm{ij}}$; Level 2: $\pi_{0 \mathrm{j}}=\gamma_{00}+u_{0 \mathrm{j}}$, and $\pi_{1 j}=-\gamma_{10}$ ) by allowing for heterogeneity in the residual variance. This change can be implemented by replacing the default specification of the variance of the residuals $e_{\mathrm{ij}} \sim N\left(0, \sigma^{2}\right)$ with the heterogenous formula $e_{\mathrm{ij}} \sim N\left(0, \sigma^{2} \exp \left[u_{7 \mathrm{j}}\right]\right)$. In this heterogenous formula, each person $\mathrm{j}$ has its own latent variability estimate, $\boldsymbol{u}_{\mathbf{7}}$. When person $\mathrm{j}=1$ has a higher value in $\boldsymbol{u}_{\mathbf{7}}$ compared to person $\mathrm{j}=\mathbf{2}$ it indicates that the construct of interest shows more variation in this person. The exponential formula is included to ensure that the variance can never become negative. Figure 1 visualizes a dataset that we generated using this model and the simdy function is provided in the supplementary material on the OSF. To better visualize individual differences in variability, we split the dataset at the median of the variability estimates and plotted data from individuals above and below the median in the left and the right panel, respectively. As shown by Figure 1, the observations in the left panel were considerably more heterogenous. The overall trend visualized using a solid line in both panels of Figure 1 is the overall trend predicted by the model after fitting it to the data. The estimates for this model are provided in Table 2, and are estimated 
using the nlme package. ${ }^{1}$

We highlight two prototypical operationalizations of individual differences in variability. Barnes et al. (Barnes et al., 2012) studied whether performance variability predicts future compensation above mean performance. As another example, Lievens et al. (2018) investigated the influence of variability in reactions to situational judgement items and used this dynamic assessment to predict performance.

Our discussion of variability constructs in this section was restricted to individual differences in variance or the standard deviation (or the second moment). However, additional variability-type constructs have been described in the literature (Eid \& Diener, 1999; Fleeson, 2001) like individual differences in the skewness or the kurtosis of a distribution (third and fourth moment). These types of constructs can also conveniently be modeled using the multilevel mixed-effects framework by specifying more complex variance functions (Bolker, 2008; Pinheiro \& Bates, 2000; Raudenbush, 1988).

\section{Skill Acquisition Constructs (Learning New Skills)}

Learning, agility, or learning agility constructs are a basic form of dynamic construct that captures individual differences in the ability to learn new skills or change behavior. We discussed this basic model earlier in the paper as a basic example of a dynamic model. Skill acquisition constructs are

\footnotetext{
${ }^{1}$ A more parsimonious approach and useful alternative to using nlme is to fit the model with random
} effects instead of fixed effects using the brms package. In this context, the variability trait can be specified using random effects by adding the assumption of a normal distribution. While the normal distribution requires stronger assumptions, it also leads to a theoretically more simple model. In practice, the variability estimates from the two variants of the model (fixed effects fitted in nlme or brms vs. random effects fitted using brms) correlate by 1 so the estimates are not affected by this choice. However, note that our analyses were conducted using simulated data. In real data, the more complex fixed-effects model may have advantages over the random effects specification. 
fundamentally individual differences in the slope of a learning curve and are thus quite common in psychology as a discipline. Most readers are also likely familiar with growth curve models. To recall, the statistical model includes the basic equation $Y_{\mathrm{ij}}=\left(\gamma_{00}+u_{0 \mathrm{j}}\right)+\left(\gamma_{10}+u_{1 \mathrm{j}}\right) T I M E_{\mathrm{i}}+e_{\mathrm{ij}}$. This equation is similar to a normal regression equation with two differences: $u_{0 \mathrm{j}}$ captures variability between individuals in the intercept and $u_{1 j}$ is an individual difference effect in the slope that captures individual differences in the degree to which people increase or decrease over time.

The model we present in Table 1 adds a quadratic effect to the basic linear model shown earlier. Quadratic effects allow modeling potential asymptotic trends and account for the fact that most learning processes show a learning curve (Ackerman, 1992; Thoresen et al., 2004). In the model in Table 1 , we did not assume systematic individual differences in this effect but it is possible that the overall skill acquisition effect can be split into a linear and an additional quadratic component.

Figure 2 shows data generated using the model in Table 1. The solid line in both panels represents the normative dynamic. Again, we split the dataset at the median of the dynamic individual difference and graphed responses from individuals with high and low values on the left and right panel, respectively. Respondents in the left panel show an increasing growth curve, whereas respondents in the right panel show now substantial growth. The model estimates for this model are again shown in Table 2.

Examples for operationalizations of skill acquisition in our literature review are the $\mathrm{Ng}$ and Lucianetti (2016) and Wang, Algozzine, Ma, and Porfeli (2011) articles. Both studies focused on a dynamic criterion. Ng and Lucianetti investigated how changes in self-efficacy are related to individual differences in the increase of innovative work behavior and Wang et al. studied how stable individual differences in early literacy relates to improvements in oral reading in $2^{\text {nd }}$-grade students.

\section{Transition Constructs (Avoiding "Loss" in Performance After Change)}

The use of transitions to understand effects of environmental change has a long tradition in 
applied research. For instance, the Hawthorne studies conducted by Mayo at the start of the $20^{\text {th }}$ century frequently included the use of transitions in time series like in the light bulb experiment (Mayo, 1933). The design is frequently used in economics where it is known as the regression discontinuity design (Antonakis et al., 2010; Y. Kim \& Ployhart, 2014; D. S. Lee \& Lemieux, 2010). However, the realization that individuals may systematically differ in their reactions to changes, and research using the design to study individual differences in transitions are more recent (Bliese et al., 2017). This use of the design is closely associated with advances in longitudinal modeling approaches (Raudenbush, 2002; Singer \& Willett, 2003) that allowed researchers to model dynamic individual differences in criteria like sleep (Bliese et al., 2006), or performance (Niessen \& Jimmieson, 2016). Especially in work and organizational psychology, transition constructs are closely linked to the concept of individual adaptability (Jundt et al., 2015; Lang \& Bliese, 2009; Ployhart \& Bliese, 2006).

Table 1 includes a discontinuous change model with a transition as typical statistical model specification. This model basically consists of two linear and quadratic growth models-one before and one after the transition-and a dummy (TA) contrasting the situation before (coded 0 ) and after the transition (1). While this model may appear relatively straightforward, there are several variants for specifying the exact coding of the change variables in the model (Bliese \& Lang, 2016). The model in Table 1 uses a basic form where the TIME variable starts at 0 and increases by 1 with each measurement occasion, the SA2 variable starts at 0 and increases by 1 until the transition, and the RA variable starts one measurement occasion after the transition and increases by 1 until the end of the observation period. In the model specification and the simulated data, individuals differ in the intercept and the transition and not in the other change variables. Table 2 shows an example for fitting this type of model to a simulated dataset. Figure 3 also visualizes this simulated dataset and the overall trend from the model in Table 2. In Figure 3, the individuals do not differ from each other prior to the transition at Time $=4$. After this transition happened, persons in the right panel have a considerably lower average level of 
performance than people in the left panel (because of the individual differences in the transition).

Examples of operationalizations using a transition dynamic construct from our systematic literature review are the studies of Bonner, Greenbaum, and Quade (2017), Wouters, De Fraine, Colpin, Van Damme, and Verschueren (2012), and Minbashian, Wood, and Beckmann (2010). Bonner et al. studied self-image protection after people engage unethical behavior. Wouters et al. (2012) studied academic self-concept after a track change in high school. Both topics deal with how individuals try to avoid loss after change-being caught engaging in unethical behavior, and forced to change track in high school. Specifically, Minbashian et al. (2010) used the degree to which people maintain their performance in the complex relative to more simple versions of a letter-problems task and used individual differences between the two as a criterion measure of adaptive performance.

\section{Reacquisition Constructs (Relearning After Change)}

Reacquisition constructs are closely related to the transition constructs discussed in the previous section in the sense that these constructs are estimated in the same type of model. The reacquisition construct are individual differences in the change rate in the second growth model after the change. Table 1 includes a discontinuous model specification with individual differences in the reacquisition effect as a typical statistical model. A typical idea is that reacquisition is a slower process that occurs after the more rapid reaction to the transition (Jundt et al., 2015; Lang \& Bliese, 2009; Niessen \& Jimmieson, 2016; Niessen \& Lang, 2020). While the reacquisition idea is intuitive, in practice, it can be challenging to interpret these types of models because reacquisition effects can either be defined relative to the overall skill acquisition rate before the change or relative to no effect/0 (Bliese \& Lang, 2016).

Figure 4 illustrates individual differences in reacquisition using a simulated dataset. Table 2 also includes the model estimates for this simulated data. The average trajectory in Figure 4 is based on these estimates. As shown in Figure 4, prior to the change at TIME $=4$, there are no differences (beyond 
chance) between the panels. Also immediately after the transition at $\operatorname{TIME}=4$, there are no differences between the two panels. However, over time, individuals in the left panel increase their performance/behavior much stronger than those in the right panel (because of individual differences in reacquisition adaptation).

Examples of operationalizations of reacquisition constructs are the studies by Howe (2019) and Zhu, Wanberg, Harrison, and Diehn (2015). Howe predicted individual differences in performance adaption after change events with general mental ability. Zhu et al. focused on expatriate experiences. Both studies examined how individuals adjust after changes (performance/country).

\section{Acceleration/Deceleration Constructs (Losing or Gaining Energy By Displaying the Behavior)}

In fields outside psychology, the idea of dynamic models is typically more narrowly defined and typically applies to models where past occurrences have a lagged effect on future situations (also known as order 1 autocorrelation). In economics, these models are known as dynamic panel models, and in biology they are typically simply known as dynamic models (for references see Table 1). However, these types of models also have a long tradition in psychological research and have been discussed especially in motivational self-regulation research, and in the context of item-order effects in psychometrics. One typical rationale behind dynamic models is that past behavior may make another display of a behavior in the future less likely because some motivational resource or reservoir is consumed (deceleration). Another rationale is that past behavior may increase a reservoir (e.g., a skill) that makes it disproportionately easier/likely to show the behavior in the future. Models typically differ in how long past behavior affects future behavior and the exact mechanisms proposed in the models. Especially deceleration models discussed in the literature typically vary in how much time back earlier behavior dampens subsequent behavior. Some models only view the immediate previous item/behavior as having an impact (e.g., Atkinson \& Birch, 1970; Lang, 2014; Tuerlinckx et al., 2002), other authors have suggested that the entire observation session has an impact (Lang, 2014; Lang \& Tay, 2021), and again 
other authors have suggested that people get pulled back to an underlying stable level (also discussed as an attractor strength or a set point, see Lucas et al., 2004; Sosnowska, Hofmans, et al., 2019; Sosnowska, Kuppens, et al., 2019). A challenge in dynamic models with continuous lagged variables can be that measurement error gets carried over in the dynamic processes. However, these types of bias are typically smaller when a dichotomous yes/no process is involved that can make sense when it resembles occurrences in the real world (e.g., winning a game, maintaining a relationship, or passing an exam). Most dynamic models describe what we referred to as "normative dynamics" earlier in this paper. While dynamic models frequently include individual differences, these individual differences are typically not itself dynamic and refer to the dynamic process itself. In the self-regulation literature, the dynamic processes have typically been discussed as potentially concealing underlying individual differences (Atkinson \& Birch, 1970). The idea that acceleration/deceleration processes itself can differ across individuals is more recent (Carver \& Scheier, 1998; Lang, 2014; Revelle, 1986). In the statistical model specifications in Table 2, the CS effect denotes consummatory strength and captures the normative dynamic part of the acceleration/deceleration effect. The variance in the CS effect, in contrast, models the individual differences between persons in the CS effect. Figure 5 then shows how these individual differences affect observed data. People with a strong CS effect (left panel in Figure 5) develop a pattern where their behavior stays at a modest level. Each increase in the behavior is counted by a subsequent decrease (because of the CS effect). In contrast, persons with a low CS effect (right panel in Figure 5) have no such stable pattern and develop different trajectories similar to a normal growth model with variance in the slopes.

Examples of operationalizations of acceleration/deceleration ideas from our literature review include the studies by Ballard, Yeo, Loft, Vancouver, and Neal (2016) and Chawla, Gabriel, da Motta Veiga, and Slaughter (2019). Ballard et al. (2016) focused on decision making in the presence of multiple goals. Chawla et al. (2019) studied self-regulation in job searches. Both papers postulate dynamic 
systems where behavior loses its energy the longer it is executed. Both studies also discuss factors that may affect the dynamic behavior.

\section{Integration/Dissolution Constructs (Behavior Becomes More or Less Uniform)}

The final dynamic construct in the typology is somewhat related to the variability models discussed earlier. However, in integration/dissolution constructs the focus is not on a constant level of variability that is present, but instead on people's tendency to show either more uniform or less uniform behavior over time. In the individual differences literature, theories focusing on integration or dissolution have been discussed in the context of models of personality integration during youth or resilience. Ability uniformity in the context of Spearman's so-called law of diminishing returns, or studies on the development of the positive manifold are examples from the intelligence literature. Another context where integration/dissolution ideas recently have been discussed is in the use of network models to model changes in relations between items/symptoms across time (Costantini et al., 2019; Miers et al., 2020). Longitudinal network models were originally developed to study social relations (Niezink et al., 2019) but when network models are applied to capture relations between items/symptoms the model is an alternative representation of factor models (Kan et al., 2020; van Bork et al., 2019). Especially indices capturing individual differences in changes in the centrality of a network capture the idea of changes in integration/dissolution.

Table 1 provides a typical model specification for an integration/dissolution model. Like the variability model discussed earlier, this model also has a specific TIME effect for each person. ${ }^{2}$ Table 2

\footnotetext{
${ }^{2}$ Again, the model can also be fitted using the brms package (Bürkner, 2017) with the additional
} assumption that the residual effects are normally distributed. This approach leads to a more simple model. Again, the estimates for the integration/dissolution effects for each person were correlated by 1 between the two 
provides the model estimates for a simulated dataset, and Figure 6 graphs this dataset. As shown in Figure 6, there were marked differences in the degree to which observations become more similar to each other over time between individuals scoring high and those low on the integration/dissolution construct. At the start of the observation period at TIME $=0$, the individuals in both panels differ quite considerably. Over time, the individuals in the left panel with a strong integration effect become much more homogenous than the persons in the right panel with a weak integration effect.

We did not find studies focusing on true individual integration or dissolution but we have found a few articles studying integration in group contexts. Two example papers that include an integration/dissolution construct from our literature review are Grand, Braun, Kuljanin, Kozlowski, and Chao (2016) and S.M. Lee and Farh (2019). Grand et al. (2016) studied team cognition and investigated how changes in individual level processes result in changes in team-level criteria, whereas S.M. Lee and Farh (2019) studied dynamic leadership emergence in a team creativity and innovation setting. Both sets of ideas are conceptually similar to an integration/dissolution construct because both papers focus on how individual differences lead to more uniform behavior.

\section{Literature Review}

In a next step, we were also interested in the degree to which the typology and the constructs in it are studied in the applied psychology literature in recent years. We therefore surveyed the last 15 years of three work and organizational psychology journals-Journal of Applied Psychology, Personnel Psychology, and Human Performance-and the leading educational psychology journal-Journal of Educational Psychology. Our goal was to identify the frequency of each of the categories of the typology, potential research gaps in the literature, and also potential additional conceptualizations in the existing

versions of the model. Again, note that our analyses were conducted using simulated data. In real data, the more complex fixed-effects model may have advantages over the random effects specification. 
literature as a further check and validiation of the typology. We also classified the degree to which the dynamic individual differences constructs focused on assessment of predictor constructsand criteria and analyzed differences between journals and time trends.

\section{Systematic Literature Search}

Our systematic literature search focused on research published in the last 15 years (2005-2020) in four major journals - the Journal of Applied Psychology, Personnel Psychology, Human Performance, and Journal of Educational Psychology. We focused on these four prominent journals to cover main research trends. The Journal of Applied Psychology and Personnel Psychology were included because these two journals currently have the highest prestige in the field of work and organizational psychology and also have held this position across the last 20 years (Highhouse et al., 2020). Human Performance was added because it aims to link applied psychology and individual differences. The Journal of Educational Psychology is typically the most highly ranked within educational psychology. In interpreting the findings, it is important to be aware that Personnel Psychology and Human Performance are generally much smaller journals than the other two journals and publish a smaller number of articles each year. Accordingly, the interpretation of the findings across categories is meaningful but it is not meaningful to compare the total number between journals as an indicator of the number of overall articles the journal publishes on dynamic phenomena.

We describe our literature search process in a flow chart in Figure 7. To identify articles of interest, we first searched in Web of Science topic search using the terms "dynamic", "flexible", "agile", "adaptable", "adaptive", "adaptability", "within-person variability", and "intraindividual AND individual differences" for papers published from 2005 until 2020. This search resulted in 271 papers. In an initial screening, we excluded five search results that were book reviews, a correction note, and a retracted article. We then analyzed the remaining 266 articles for eligibility. We excluded 39 articles that did not study dynamic constructs. The final sample size of eligible articles was 227: 134 papers from the Journal 
of Applied Psychology, 23 articles form Personnel Psychology, 13 from Human Performance, and 57 articles from the Journal of Educational Psychology. The complete dataset is available (https://osf.io/x827q/?view_only=173fe10712ac48bab3c44b9fd18fbf24) on the Open Science Framework (OSF).

In a first step, we coded each article into one of the five following categories: Main effects labelled as dynamic, mentioned in the literature, normative dynamics, questionnaire asking for dynamic individual differences, or dynamic individual differences. Main effects labelled as dynamic includes articles that studied the relationship between two or more variables using the term dynamic to describe this relationship but did not actually include any dynamic effects. We coded articles as mentioned in the literature when they discussed or mentioned normative dynamics or dynamic individual differences in the introduction or discussion section but did not study it. Normative dynamics describes articles studying dynamic changes in main effects that to not differ between individuals. We coded studies as using questionnaires asking for dynamic individual differences when they used a questionnaire directly measuring change, such as questionnaires asking for adaptive performance. Finally, we coded articles as dynamic individual differences when they studied individual differences in dynamic changes.

In a second step, we proceeded to code all articles in the dynamic individual differences category. For each article, we made two classification decisions. First, we categorized articles using the proposed six conceptualizations from the typology described in the previous subsection. We coded articles for fit with the six conceptualizations of the dynamic individual difference constructs. Accordingly, we did not limit the coding categories to the statistical formulation in Table 1, but also included other statistical implementations such as standard deviation as operationalization of variation. Second, we coded whether papers focused on dynamic assessment, dynamic criteria, or on both dynamic assessment and dynamic criteria. 


\section{Results and Discussion}

Table 3 provides an overview of both coding steps and distinguishes between the four journals. The first coding step is reported in the upper part of Table 3. From the 227 articles, 21 labelled main effects as dynamic, 29 mentioned dynamic constructs in their literature review, 86 articles studied normative dynamics, 15 articles measured dynamic individual differences directly using a questionnaire, and 76 articles studied dynamic individual differences. Thus, there are more studies focusing only on normative dynamics than on dynamic individual differences, but the difference is not large.

In the second coding step we coded the 76 papers studying dynamic individual differences into the six dynamic constructs from the typology. 14 articles studied more than one dynamic individual difference construct resulting in 90 total codings. Results are in the lower part of Table 3. From the 90 codings, 29 (32.22\%) belonged into the variability, 36 (40.00\%) into skill acquisition, $8(8.89 \%)$ into the transition, $7(7.78 \%)$ into the reacquisition, 5 (5.56\%) into the acceleration/deceleration, and 5 (5.56\%) into the integration/dissolution categories. The findings, thus, suggest that especially variability and skill acquisition are frequently studied. In contrast, transition, reacquisition, acceleration/deceleration constructs, and integration/dissolution constructs are less frequently investigated-possibly also because these constructs require a more complex design.

Table 3 also includes more fine-grained information on the journals in which the respective papers in each category were published. As would likely be expected, the Journal of Educational Psychology generally had a stronger focus on skill acquisition constructs (relative to the other constructs) than the three work and organizational psychology journals.

Table 4 shows the results for the classification into categories depending on whether the articles focused on dynamic assessment or dynamic criteria. From the 90 codings, 19 (21.11\%) focused on dynamic assessment, 61 (67.78\%) focused on dynamic criteria, and $10(11.11 \%)$ used both dynamic assessment and dynamic criteria. This analysis suggests that a majority of the authors decided to focus 
on one specific dynamic individual difference phenomenon and link this phenomenon to other, more conventional, type of measures.

To study how research on dynamic constructs emerged over time, we organized our findings in three periods: 2005 to 2009, 2010 to 2014, and 2015 to 2020. Table 5 shows that the total number of articles increased over the years with 57 articles in the first period, 79 in the second period, and 91 in the third period. Note that the third period included articles published from 2015 until September 2020 and, thus, includes 9 months more than the other periods (16 articles from 2020 were coded), so there is no increase between the second and third period. An interesting observation is that the number of articles coded with categories that did not study change themselves (i.e. main effects labelled as dynamic, mentioned in the literature, and questionnaire asking for dynamic individual differences) did not substantially increase over time. In contrast, both the number of articles studying normative dynamics (from 21 in the first period to 28 and then 37 in the following periods) and dynamic individual differences (from 16 in the first period to 28 and then 33 in the following periods) increased substantially over time. A possible explanation is that new theories on dynamic constructs and statistical tools to study them were developed over time and fostered research on normative dynamics and dynamic individual differences.

\section{Contrasting Competing Dynamic Explanations}

In the last sections, we described an organizing framework for the literature on dynamic individual differences by describing six prototypical conceptualizations. An important challenge for researchers who seek to study dynamic individual differences and other complex phenomena is the fact that it may be difficult to choose among alternative models.

In this section, we describe an approach allowing researchers to estimate an $\mathrm{R}^{2}$ that enables comparisons between dynamic individual differences models. First and foremost, the choice of a model should likely be informed by substantive theory about phenomena. However, it is still possible that 
researchers are confronted with competing dynamic explanations for observed patterns or need to evaluate how relevant two potentially complementary explanations could be in their data. Another challenge that researchers frequently face is to provide effect size information for their models (Eby et al., 2020). For common regression models, $R^{2}$ values provide a convenient way to test how much variance a particular predictor or a set of predictors explains and to quantify how well two competing models explain the data. However, for more complex models the choice of an effect size and model fitting statistic is somewhat more challenging. A variety of different $R^{2}$ statistics exist for multilevel mixed-effects models (LaHuis et al., 2014; Rights \& Sterba, 2019). These statistics capture different elements of these models and most rely either on variance components or the residuals. However, these approaches have limited usefulness for some of the dynamic individual differences models we described because these models also include change in the residuals so that these $R^{2}$ values can actually decrease even when the model fit improves.

One potential solution to these issues that has recently been suggested (Lang, Bliese, \& Runge, 2019 ) is the use of likelihood-based $\mathrm{R}^{2}$ statistics $\left(R_{L R}^{2}\right) \cdot R_{L R}^{2}$ has long existed in the literature (Magee, 1990) and was originally developed to compare gIms and OLS regression models but has rarely been used in the past. An important advantage of $R_{L R}^{2}$ is that this statistic can account for all elements of the model and is thus also suited to capture more complex dynamic individual differences components. An intuitive advantage of $R_{L R}^{2}$ is that the estimate is identical to the ordinary OLS $R^{2}$ for ordinary regression models and it is thus possible to also compare simple regression models with more complex models. $R_{L R}^{2}$ can be estimated using the sample size $(N)$, the likelihood ratio from a null model with only an intercept $\left(L_{0}\right)$, and the model of interest $\left(L_{M}\right)$.

$$
R_{L R}^{2}=1-\exp \left(-\frac{2}{N}\left[\log L_{M}-\log L_{0}\right]\right)
$$

It is also possible to use this formula to estimate a $\Delta R_{L R}^{2}$ by using the loglikelihood from the less complex model as $L_{0}$ instead of an intercept only model or by taking the difference between $R_{L R}^{2}$ 
estimates for two different models.

Table 6 provides an example of the use of $R_{L R}^{2}$ for comparing models on dynamic individual differences using the simulated datasets shown in Figures 1 to 6 and Table 1. Table 6 provides bold printed $R_{L R}^{2}$ for the models along the diagonal. These bold $R_{L R}^{2}$ were estimated by fitting the models to the simulated datasets that were used to generate the data. The $R_{L R}^{2}$ in off-diagonals are the result of fitting the respective incorrect models to the datasets. As indicated by Table 6, the off-diagonal values were smaller in all cases. However, it is also clear that some of the $R_{L R}^{2}$ indicate a relatively better model fit than others and thus show that some of the dynamic conceptualizations in the typology we described may pick up overlapping elements of data.

\section{Discussion}

We provided a framework for organizing, evaluating, and developing constructs and theories in future work on dynamic individual difference constructs that also gives guidance for operationalizing dynamic constructs in actual research. The typology includes six basic conceptualizations of dynamic individual differences: Variability constructs (inconsistency across situations), skill acquisition constructs (learning new skills), transition constructs (avoiding "loss" in performance after unforeseen change), reacquisition constructs (relearning after change), dynamic consumption constructs (losing energy by displaying the behavior), and dynamic integration/dissolution constructs (behavior becomes more or less uniform).

Experiences with the development of organizing typologies in past research (Chan, 1998; Harrison \& Klein, 2007) suggest that conceptual and methodological typologies can be useful in organizing novel and complex research fields, and can help researchers to better communicate their contributions and findings and can allow researchers to identify gaps in the literature. The present typology has the potential to be also helpful in this way. For instance, our systematic literature review suggests that several of the dynamic conceptualizations in the typology like individual differences in 
transition and reacquisition have so far rarely been used in educational research.

We restricted our definition of dynamic effects to effects that include a change across time. This definition excludes effects that are merely situationally specific. These boundaries, however, can be fluent. For instance, research on variability (Fleeson, 2001; Fleeson \& Jayawickreme, 2015; Lievens et al., 2018; Sosnowska, Kuppens, et al., 2019) frequently draws on ideas from the situational specificity literature to argue that variability is a result of many small if-then contingencies (Mischel \& Shoda, 1995, 1998,2008 ) that are so complex and situationally specific that they cannot fully be captured through measurement and result in individual differences in how strongly individuals adapt to situations across time. Based on our definition of dynamic effects, variability is included because it contains a clear time and continuous change idea and systematic individual differences in it. In contrast, research that studies one or a limited set of situations like, for instance, studies that build on the experimental personality psychology paradigm (Eysenck, 1996; Revelle, 2007) and examine an interaction between a personality trait and a dummy code contrasting two different situations would not be labeled dynamic. The reason is that the situational contrast dummy in these studies do not capture a dynamic individual difference. The study merely combines individual differences in a personality trait with a categorical situation variable that "deactivates" or "activates" them. The only systematic individual difference is thus the personality trait. Only when a study captures a new variable that itself is an individual difference with a (near) normal distribution component one would typically speak of dynamic individual differences. However, again, the boundaries can be somewhat fluent. For instance, a researcher could argue that individuals differ in the degree to which they react to situation $A$ vs. situation $B$ and define a random effect/individual differences variable. As soon as a time component would be added this type of crosslevel individual difference variable (e.g., Ilies et al., 2010, 2017; Lanaj \& Johnson, 2016) would be dynamic on the basis of our definition. In our framework, an effect of this type would fit into the classification of a transition effect. 
Another element that we did not include in the taxonomy are studies that investigate measurement properties like various forms of measurement invariance across time. The reason is that measurement invariance models (e.g., Vandenberg \& Lance, 2000) do not include an individual difference variable that refers to time. However, again, the boundaries are somewhat fluent. Some of the dynamic individual differences constructs we discussed - when not properly included in the model would also cause a lack of invariance. For instance, the integration/disolution type of effects can be seen as capturing systematic individual differences in a lack of metric invariance that is driven by a dynamic individual difference construct. Likewise, skill acquisition, transition, and reacquisition effects capture a systematic form of a lack of scalar invariance.

In summary, researchers can quickly examine whether a study design would fit the definition of a dynamic individual difference by first checking whether a random effect or construct is involved that captures something about time. We believe that this definition is useful because it provides a clear guideline to separate dynamic individual differences from other study designs.

\section{Limitations}

A potential limitation of the current work is that the typology is restricted to dynamic constructs that can be conveniently applied and modeled using organizational data and does not include complex computational models (e.g., Vancouver et al., 2010). However, in many cases also complex computational models include core components and need to be validated with actual organizational data at which point the present typology allows researchers to find a workable way to do so.

Another limitation of the models we demonstrated is that these models are for continuous dependent variables. We deliberately made this choice for demonstration purposes. However, especially in assessment, researchers may frequently also be interested in models for dichotomous or ordinal criteria because they seek to use items and no longer tests or scales that can be scored continuously. For most of the constructs in the typology, models of this type exist and we refer readers to the literature 
we cited for such models.

\section{Practical Implications}

The described framework has a couple of direct practical implications for the field of applied psychology. First and foremost, we believe that the framework also can be fruitful in developing new theory and study design in several areas. In relation to the overall number of articles published in the journals we reviewed, the number of papers that study transition, reacquisition, acceleration/deceleration or integration/dissolution constructs was quite small in our literature review (see Table 5). Accordingly, we believe that it is likely that several research areas exist in applied psychology that would benefit from the use of these dynamic individual difference constructs to gain deeper insights into time-related change. This being said, there is a current trend in the field to more broadly include transition and reacquisition concepts that is partly driven by a recent review (Bliese et al., 2017) and the Coronavirus pandemic. The later situation has likely led to new and renewed interest.

Second, the taxonomy and models proposed in this review may be also useful in other fields of psychology, beyond the work place or education. Dynamic consumption constructs, for example, may be very useful for studying the impact of demonstrating alternative and newly learned behaviors in therapeutic interventions, whereas dynamic integration/dissolution constructs are particularly well suited to model identity diffusion versus integration in the study of adolescent personality and its distinction from emerging borderline personality pathology.

Third, the present paper also makes a novel contribution by putting a variety of dynamic individual differences construct into a framework that makes these models comparable. For the purpose of developing a research field, it is critically important to be able to compare competing theoretical explanations with each other. Modeling approaches can frequently appear diverse, complex, and seemingly unrelated. However, many models used in applied psychology are actually closely related. Our paper puts key dynamic concepts into the mixed-effects modeling framework so that authors can use 
our basic code to quickly evaluate whether a novel/alternative dynamic individual differences concept has value in their data. 


\section{References}

Abrahams, L., Pancorbo, G., Primi, R., Santos, D., Kyllonen, P., John, O. P., \& De Fruyt, F. (2019). Socialemotional skill assessment in children and adolescents: Advances and challenges in personality, clinical, and educational contexts. Psychological Assessment, 31(4), 460-473. https://doi.org/10.1037/pas0000591

Ackerman, P. L. (1992). Predicting individual differences in complex skill acquisition: dynamics of ability determinants. Journal of Applied Psychology, 77(5), 598-614. https://doi.org/https://doi.org/10.1037/0021-9010.77.5.598

Antonakis, J., Bendahan, S., Jacquart, P., \& Lalive, R. (2010). On making causal claims: A review and recommendations. The Leadership Quarterly, 21(6), 1086-1120. https://doi.org/10.1016/j.leaqua.2010.10.010

Asparouhov, T., Hamaker, E. L., \& Muthén, B. (2018). Dynamic Structural Equation Models. Structural Equation Modeling: A Multidisciplinary Journal, 25(3), 359-388. https://doi.org/10.1080/10705511.2017.1406803

Atkinson, J. W., \& Birch, D. (1970). The dynamics of action. John Wiley.

Ballard, T., Yeo, G., Loft, S., Vancouver, J. B., \& Neal, A. (2016). An integrative formal model of motivation and decision making: The MGPM*. Journal of Applied Psychology, 101(9), 1240-1265. https://doi.org/10.1037/apl0000121

Barnes, C. M., Reb, J., \& Ang, D. (2012). More than just the mean: Moving to a dynamic view of performance-based compensation. Journal of Applied Psychology, 97(3), 711-718. https://doi.org/10.1037/a0026927

Bates, D. M., Maechler, M., Bolker, B., \& Walker, S. (2015). Fitting Linear Mixed-Effects Models using 
Ime4. Journal of Statistical Software. http://arxiv.org/abs/1406.5823

Bliese, P. D., Adler, A. B., \& Flynn, P. J. (2017). Transition Processes: A Review and Synthesis Integrating Methods and Theory. Annual Review of Organizational Psychology and Organizational Behavior, 4(1), 263-286. https://doi.org/10.1146/annurev-orgpsych-032516-113213

Bliese, P. D., \& Lang, J. W. B. (2016). Understanding relative and absolute change in discontinuous growth models. Organizational Research Methods, 19(4), 562-592. https://doi.org/10.1177/1094428116633502

Bliese, P. D., \& Ployhart, R. E. (2002). Growth modeling using random coefficient models: Model building, testing, and illustrations. Organizational Research Methods, 5, 362-387. https://doi.org/10.1177/109442802237116

Bliese, P. D., Wesenstein, N. J., \& Balkin, T. J. (2006). Age and individual variability in performance during sleep restriction. Journal of Sleep Research, 15(4), 376-385. https://doi.org/10.1111/j.13652869.2006.00557.x

Bolker, B. (2008). Ecological Models and Data in R. Princeton University Press.

Bonner, J. M., Greenbaum, R. L., \& Quade, M. J. (2017). Employee unethical behavior to shame as an indicator of self-image threat and exemplification as a form of self-image protection: The exacerbating role of supervisor bottom-line mentality. Journal of Applied Psychology, 102(8), 12031221. https://doi.org/10.1037/apl0000222

Borsboom, D. (2006). The attack of the psychometricians. Psychometrika, 71, 425-440. https://doi.org/10.1007/s11336-006-1447-6

Bryk, A. S., \& Raudenbush, S. W. (1987). Application of hierarchical linear models to assessing change. Psychological Bulletin, 101, 147-158. https://doi.org/10.1037//0033-2909.101.1.147 
Bürkner, P.-C. (2017). brms : An R Package for Bayesian Multilevel Models Using Stan. Journal of Statistical Software, 80(1). https://doi.org/10.18637/jss.v080.i01

Carver, C. S., \& Scheier, M. F. (1998). On the self-regulation of behavior. Cambridge University Press.

Chan, D. (1998). Functional relations among constructs in the same content domain at different levels of analysis: A typology of composition models. Journal of Applied Psychology, 83, 234-246. https://doi.org/10.1037/0021-9010.83.2.234

Chawla, N., Gabriel, A. S., da Motta Veiga, S. P., \& Slaughter, J. E. (2019). Does feedback matter for job search self-regulation? It depends on feedback quality. Personnel Psychology, 72(4), 513-541. https://doi.org/10.1111/peps.12320

Chen, G. (2005). Newcomer Adaptation in Teams: Multilevel Antecedents and Outcomes. Academy of Management Journal, 48(1), 101-116. https://doi.org/10.5465/amj.2005.15993147

Connor, C. M. D., Spencer, M., Day, S. L., Giuliani, S., Ingebrand, S. W., McLean, L., \& Morrison, F. J. (2014). Capturing the complexity: Content, type, and amount of instruction and quality of the classroom learning environment synergistically predict third graders' vocabulary and reading comprehension outcomes. Journal of Educational Psychology, 106(3), 762-778. https://doi.org/10.1037/a0035921

Costantini, G., Richetin, J., Preti, E., Casini, E., Epskamp, S., \& Perugini, M. (2019). Stability and variability of personality networks. A tutorial on recent developments in network psychometrics. Personality and Individual Differences, 136, 68-78. https://doi.org/10.1016/j.paid.2017.06.011

Debusscher, J., Hofmans, J., \& De Fruyt, F. (2016). Do personality states predict momentary task performance? The moderating role of personality variability. Journal of Occupational and Organizational Psychology, 89(2), 330-351. https://doi.org/10.1111/joop.12126 
Dejonckheere, E., Mestdagh, M., Houben, M., Rutten, I., Sels, L., Kuppens, P., \& Tuerlinckx, F. (2019). Complex affect dynamics add limited information to the prediction of psychological well-being. In Nature Human Behaviour (Vol. 3, Issue 5, pp. 478-491). https://doi.org/10.1038/s41562-019-05550

DeRue, D. S., Ashford, S. J., \& Myers, C. G. (2012). Learning Agility: In Search of Conceptual Clarity and Theoretical Grounding. Industrial and Organizational Psychology, 5(3), 258-279. https://doi.org/10.1111/j.1754-9434.2012.01444.x

Duncan, T. E., Duncan, S. C., Strycker, L. A., Li, F., \& Alpert, A. (1999). An introduction to latent variable growth curve modeling: Concepts, issues, and applications. Erlbaum.

Eby, L. T., Shockley, K. M., Bauer, T. N., Edwards, B., Homan, A. C., Johnson, R., Lang, J. W. B., Morris, S. B., \& Oswald, F. L. (2020). Methodological checklists for improving research quality and reporting consistency. Industrial and Organizational Psychology, 13(1), 76-83. https://doi.org/10.1017/iop.2020.14

Eid, M., \& Diener, E. (1999). Intraindividual variability in affect: Reliability, validity, and personality correlates. Journal of Personality and Social Psychology, 76, 662-676. https://doi.org/10.1037//0022-3514.76.4.662

Eysenck, H. J. (1996). Personality and the experimental study of education. European Journal of Personality, 10(5), 427-439. https://doi.org/10.1002/(SICI)1099-0984(199612)10:5<427::AIDPER254>3.0.CO;2-H

Farrell, J. N., \& McDaniel, M. A. (2001). The stability of validity coefficients over time: Ackerman's (1988) model and the General Aptitude Test Battery. Journal of Applied Psychology, 86(1), 60-79. https://doi.org/10.1037/0021-9010.86.1.60 
Finnigan, K. M., \& Vazire, S. (2018). The incremental validity of average state self-reports over global self-reports of personality. Journal of Personality and Social Psychology, 115(2), 321-337. https://doi.org/10.1037/pspp0000136

Fleeson, W. (2001). Toward a structure- and process-integrated view of personality: Traits as density distributions of states. Journal of Personality and Social Psychology, 80, 1011-1027. https://doi.org/10.1037//0022-3514.80.6.1011

Fleeson, W., \& Gallagher, P. (2009). The implications of Big Five standing for the distribution of trait manifestation in behavior: Fifteen experience-sampling studies and a meta-analysis. Journal of Personality and Social Psychology, 97(6), 1097-1114. https://doi.org/10.1037/a0016786

Fleeson, W., \& Jayawickreme, E. (2015). Whole Trait Theory. Journal of Research in Personality, 56, 8292. https://doi.org/10.1016/j.jrp.2014.10.009

Flügel, J. C. (1929). Practice, fatigue, and oscillation. British Journal of Psychology, 7, Monograph Supplement, 13.

Grand, J. A., Braun, M. T., Kuljanin, G., Kozlowski, S. W. J., \& Chao, G. T. (2016). The dynamics of team cognition: A process-oriented theory of knowledge emergence in teams. Journal of Applied Psychology, 101(10), 1353-1385. https://doi.org/10.1037/apl0000136

Gucciardi, D. F., Crane, M., Ntoumanis, N., Parker, S. K., Thøgersen-Ntoumani, C., Ducker, K. J., Peeling, P., Chapman, M. T., Quested, E., \& Temby, P. (2018). The emergence of team resilience: A multilevel conceptual model of facilitating factors. Journal of Occupational and Organizational Psychology, 91(4), 729-768. https://doi.org/10.1111/joop.12237

Harrison, D. A., \& Klein, K. J. (2007). What's the difference? Diversity constructs as separation, variety, or disparity in organizations. Academy of Management Review, 32, 1199-1228. 
https://doi.org/10.5465/AMR.2007.26586096

Hedeker, D., Mermelstein, R. J., \& Demirtas, H. (2008). An application of a mixed-effects location scale model for analysis of Ecological Momentary Assessment (EMA) data. Biometrics, 64, 627-634. https://doi.org/10.1111/j.1541-0420.2007.00924.x

Highhouse, S., Zickar, M. J., \& Melick, S. R. (2020). Prestige and relevance of the scholarly journals: Impressions of SIOP members. Industrial and Organizational Psychology, 1-18. https://doi.org/10.1017/iop.2020.2

Howe, M. (2019). General mental ability and goal type as antecedents of recurrent adaptive task performance. Journal of Applied Psychology, 104(6), 796-813. https://doi.org/10.1037/apl0000379

Ilies, R., Dimotakis, N., \& De Pater, I. E. (2010). Psychological and physiological reactions to high workloads: Implications for well-being. Personnel Psychology, 63(2), 407-436. https://doi.org/10.1111/j.1744-6570.2010.01175.x

Ilies, R., Liu, X. Y., Liu, Y., \& Zheng, X. (2017). Why do employees have better family lives when they are highly engaged at work? Journal of Applied Psychology, 102(6), 956-970. https://doi.org/10.1037/apl0000211

Jahng, S., Wood, P. K., \& Trull, T. J. (2008). Analysis of affective instability in ecological momentary assessment: Indices using successive difference and group comparison via multilevel modeling. Psychological Methods, 13(4), 354-375. https://doi.org/10.1037/a0014173

Jundt, D. K., Shoss, M. K., \& Huang, J. L. (2015). Individual adaptive performance in organizations: A review. Journal of Organizational Behavior, 36(S1), S53-S71. https://doi.org/10.1002/job.1955

Kan, K.-J., de Jonge, H., van der Maas, H. L. J., Levine, S. Z., \& Epskamp, S. (2020). How to Compare Psychometric Factor and Network Models. Journal of Intelligence, 8(4), 35. 
https://doi.org/10.3390/jintelligence8040035

Keele, L., \& Kelly, N. J. (2006). Dynamic Models for Dynamic Theories: The Ins and Outs of Lagged Dependent Variables. Political Analysis, 14(2), 186-205. https://doi.org/10.1093/pan/mpj006

Kehr, T. (1916). Versuchsanordnung zur experimentellen Untersuchung einer kontinuierlichen Aufmerksamkeitsleistung. Zeitschrift Für Angewandte Psychologie, 11, 465-479.

Kim, Y., \& Ployhart, R. E. (2014). The effects of staffing and training on firm productivity and profit growth before, during, and after the Great Recession. Journal of Applied Psychology, 99(3), 361389. https://doi.org/10.1037/a0035408

Kim, Y. S., Petscher, Y., Schatschneider, C., \& Foorman, B. (2010). Does growth rate in oral reading fluency matter in predicting reading comprehension achievement? Journal of Educational Psychology, 102(3), 652-667. https://doi.org/10.1037/a0019643

LaHuis, D. M., Hartman, M. J., Hakoyama, S., \& Clark, P. C. (2014). Explained Variance Measures for Multilevel Models. Organizational Research Methods, 17(4), 433-451. https://doi.org/10.1177/1094428114541701

Lanaj, K., \& Johnson, R. E. (2016). Benefits of transformational behaviors for leaders: A daily investigation of leader behaviors and need fulfillment. Journal of Applied Psychology, 101(2), 237251. https://doi.org/10.1037/apl0000052

Lang, J. W. B. (2014). A dynamic Thurstonian item response theory of motive expression in the picture story exercise: Solving the internal consistency paradox of the PSE. Psychological Review, 121, 481500. https://doi.org/10.1037/a0037011

Lang, J. W. B., \& Bliese, P. D. (2009). General mental ability and two types of adaptation to unforeseen change: applying discontinuous growth models to the task-change paradigm. Journal of Applied 
Psychology, 94(2), 411-428. https://doi.org/10.1037/a0013803

Lang, J. W. B., Bliese, P. D., \& Adler, A. B. (2019). Opening the Black Box: A Multilevel Framework for Studying Group Processes. Advances in Methods and Practices in Psychological Science, 2(3), 271287. https://doi.org/10.1177/2515245918823722

Lang, J. W. B., Bliese, P. D., \& Runge, J. M. (2019). Detecting Consensus Emergence in Organizational Multilevel Data: Power Simulations. Organizational Research Methods, 109442811987395. https://doi.org/10.1177/1094428119873950

Lang, J. W. B., Lievens, F., De Fruyt, F., Zettler, I., \& Tackett, J. L. (2019). Assessing meaningful withinperson variability in Likert-scale rated personality descriptions: An IRT tree approach. Psychological Assessment, 31(4), 474-487. https://doi.org/10.1037/pas0000600

Lang, J. W. B., \& Tay, L. (2021). The science and practice of item response theory in organizations. Annual Review of Organizational Psychology and Organizational Behavior.

Lee, D. S., \& Lemieux, T. (2010). Regression Discontinuity Designs in Economics. Journal of Economic Literature, 48(2), 281-355. https://doi.org/10.1257/jel.48.2.281

Lee, S. M., \& Farh, C. I. C. (2019). Dynamic leadership emergence: Differential impact of members' and peers' contributions in the idea generation and idea enactment phases of innovation project teams. Journal of Applied Psychology, 104(3), 411-432. https://doi.org/10.1037/apl0000384

LePine, J. A., Colquitt, J. A., \& Erez, A. (2000). Adaptability to changing task contexts: Effects of general cognitive ability, conscientiousness, and openness to experience. Personnel Psychology, 53(3), 563-593. https://doi.org/10.1111/j.1744-6570.2000.tb00214.x

Lester, H. F., Cullen-Lester, K. L., \& Walters, R. W. (2019). From Nuisance to Novel Research Questions: Using Multilevel Models to Predict Heterogeneous Variances. Organizational Research Methods, 
109442811988743. https://doi.org/10.1177/1094428119887434

Lievens, F., Lang, J. W. B., De Fruyt, F., Corstjens, J., Van de Vijver, M., \& Bledow, R. (2018). The predictive power of people's intraindividual variability across situations: Implementing whole trait theory in assessment. Journal of Applied Psychology, 103(7), 753-771.

https://doi.org/10.1037/apl0000280

Lucas, R. E., Clark, A. E., Georgellis, Y., \& Diener, E. (2004). Unemployment alters the set point for life satisfaction. Psychological Science, 15(1), 8-13. https://doi.org/10.1111/j.09637214.2004.01501002.x

Magee, L. (1990). R 2 Measures Based on Wald and Likelihood Ratio Joint Significance Tests. The American Statistician, 44(3), 250. https://doi.org/10.2307/2685352

Mayo, E. (1933). The human problems of an industrial civilization. Macmillan.

Merriam-Webster. (2019). dynamic. Author. https://www.merriam-webster.com/dictionary/dynamic Mestdagh, M., Pe, M., Pestman, W., Verdonck, S., Kuppens, P., \& Tuerlinckx, F. (2018). Sidelining the mean: The relative variability index as a generic mean-corrected variability measure for bounded variables. Psychological Methods, 23(4), 690-707. https://doi.org/10.1037/met0000153.supp

Miers, A. C., Weeda, W. D., Blöte, A. W., Cramer, A. O. J., Borsboom, D., \& Westenberg, P. M. (2020). A cross-sectional and longitudinal network analysis approach to understanding connections among social anxiety components in youth. Journal of Abnormal Psychology, 129(1), 82-91. https://doi.org/10.1037/abn0000484

Minbashian, A., Wood, R. E., \& Beckmann, N. (2010). Task-contingent conscientiousness as a unit of personality at work. Journal of Applied Psychology, 95(5), 793-806. https://doi.org/10.1037/a0020016 
Mischel, W. (1968). Personality and Assessment. Wiley.

Mischel, W., \& Shoda, Y. (1995). A cognitive-affective system theory of personality: Reconceptualizing situations, dispositions, dynamics, and invariance in personality structure. Psychological Review, 102(2), 246-268. https://doi.org/10.1037/0033-295X.102.2.246

Mischel, W., \& Shoda, Y. (1998). Reconciling processing dynamics and personality dispositions. Annual Review of Psychology, 49, 229-258. https://doi.org/10.1146/annurev.psych.49.1.229

Mischel, W., \& Shoda, Y. (2008). Toward a unified theory of personality: Integrating dispositions and processing dynamics within the cognitive-affective processing system. In O. P. John, R. W. Robins, \& L. A. Pervin (Eds.), Handbook of personality: Theory and research (pp. 208-241). The Guilford Press. https://psycnet.apa.org/record/2008-11667-007

Mitchell, D. J., Tal, E., \& Chang, H. (2017). The making of measurement: Editors' introduction. Studies in History and Philosophy of Science Part A, 65-66, 1-7. https://doi.org/10.1016/j.shpsa.2017.10.001

Ng, T. W. H., \& Lucianetti, L. (2016). Within-individual increases in innovative behavior and creative, persuasion, and change self-efficacy over time: A social-cognitive theory perspective. Journal of Applied Psychology, 101(1), 14-34. https://doi.org/10.1037/apl0000029

Niessen, C., \& Jimmieson, N. L. (2016). Threat of resource loss: The role of self-regulation in adaptive task performance. Journal of Applied Psychology, 101(3), 450-462. https://doi.org/10.1037/apl0000049

Niessen, C., \& Lang, J. W. B. (2020). Cognitive control strategies and adaptive performance in a complex work task. Journal of Applied Psychology. https://doi.org/10.1037/apl0000830

Niezink, N. M. D., Snijders, T. A. B., \& van Duijn, M. A. J. (2019). No Longer Discrete: Modeling the Dynamics of Social Networks and Continuous Behavior. Sociological Methodology, 49(1), 295-340. 
https://doi.org/10.1177/0081175019842263

Pervin, L. A. (1994). A Critical Analysis of Current Trait Theory. Psychological Inquiry, 5(2), 103-113. https://doi.org/10.1207/s15327965pli0502_1

Pinheiro, J. C., \& Bates, D. M. (2000). Mixed-effects models in S and S-PLUS. Springer.

Pinheiro, J. C., Bates, D. M., DebRoy, S., Sarkar, D., \& Team, R. C. (2017). nlme: Linear and nonlinear mixed effects models. $R$ package version 3.1-131. https://cran.r-project.org/package=nlml

Ployhart, R. E., \& Bliese, P. D. (2006). Individual Adaptability (I-ADAPT) Theory: Conceptualizing the Antecedents, Consequences, and Measurement of Individual Differences in Adaptability. In Understanding Adaptability: A Prerequisite for Effective Performance within Complex Environments (pp. 3-39). Elsevier. https://doi.org/10.1016/\$1479-3601(05)06001-7

Ployhart, R. E., \& Vandenberg, R. J. (2010). Longitudinal research: The theory, design, and analysis of change. Journal of Management, 36, 94-120. https://doi.org/10.1177/0149206309352110

Rast, P., Hofer, S. M., \& Sparks, C. (2012). Modeling individual differences in within-person variation of negative and positive affect in a mixed effects location scale model using BUGS/JAGS. Multivariate Behavioral Research, 47(2), 177-200. https://doi.org/10.1080/00273171.2012.658328

Rast, P., MacDonald, S. W. S., \& Hofer, S. M. (2012). Intensive Measurement Designs for Research on Aging. GeroPsych, 25(2), 45-55. https://doi.org/10.1024/1662-9647/a000054

Raudenbush, S. W. (1988). Estimating change in dispersion. Journal of Educational and Behavioral Statistics, 13, 148-171. https://doi.org/10.3102/10769986013002148

Raudenbush, S. W. (2002). Hierarchical linear models and experimental design. In Applied analysis of variance in behavioral science (pp. 459-496). 
http://books.google.com/books?hl=en\&lr=\&id=P_1cAVvrVgoC\&oi=fnd\&pg=PA459\&dq=Hierarchica I+linear+models+and+experimental+design\&ots=uL9B5s_zIR\&sig=_cX2K9joSQX7I8gY9urZgcAAn9w

Rauthmann, J. F., Beckmann, N., Noftle, E. E., \& Sherman, R. A. (2019). Personality dynamics: A new frontier in personality psychology. Personality and Individual Differences, 136, 1. https://doi.org/10.1016/j.paid.2018.07.012

Revelle, W. (1986). Motivation and efficiency of cognitive performance. In Frontiers of motivational psychology (pp. 107-127). Springer.

Revelle, W. (2007). Experimental approaches to the study of personality. In B. Robins, C. Fraley, \& R. Krueger (Eds.), Handbook of research methods in personality psychology (pp. 37-61). New York: Guilford.

Revelle, W., \& Michaels, E. J. (1976). The theory of achievement motivation revisited: The implications of inertial tendencies. Psychological Review, 83(5), 394-404. https://doi.org/10.1037/0033295X.83.5.394

Rights, J. D., \& Sterba, S. K. (2019). Quantifying explained variance in multilevel models: An integrative framework for defining R-squared measures. Psychological Methods, 24(3), 309-338. https://doi.org/10.1037/met0000184

Ryan, A. M., \& Shim, S. S. (2012). Changes in help seeking from peers during early adolescence: Associations with changes in achievement and perceptions of teachers. Journal of Educational Psychology, 104(4), 1122-1134. https://doi.org/10.1037/a0027696

Singer, J. D., \& Willett, J. B. (2003). Applied longitudinal data analysis: Modeling change and event occurence. Oxford University Press.

Sosnowska, J., Hofmans, J., \& De Fruyt, F. (2019). Relating emotional arousal to work vigour: A dynamic 
systems perspective. Personality and Individual Differences, 136, 178-183.

https://doi.org/10.1016/j.paid.2017.06.040

Sosnowska, J., Kuppens, P., De Fruyt, F., \& Hofmans, J. (2019). A dynamic systems approach to personality: The Personality Dynamics (PersDyn) model. Personality and Individual Differences, 144(February), 11-18. https://doi.org/10.1016/j.paid.2019.02.013

Spearman, C., \& Jones, L. W. (1950). Human ability. Macmillan.

Stern, W. (1911). Die differentielle Psychologie in ihren methodischen Grundlagen. Barth.

Tal, E. (2017). Calibration: Modelling the measurement process. Studies in History and Philosophy of Science Part A, 65-66, 33-45. https://doi.org/10.1016/j.shpsa.2017.09.001

Thoresen, C. J., Bliese, P. D., Bradley, J. C., \& Thoresen, J. D. (2004). The big five personality traits and individual job performance growth trajectories in maintenance and transitional job stages. Journal of Applied Psychology, 89, 835-853. https://doi.org/10.1037/0021-9010.89.5.835

Tuerlinckx, F., De Boeck, P., \& Lens, W. (2002). Measuring needs with the Thematic Apperception Test: A psychometric study. Journal of Personality and Social Psychology, 82, 448-461. https://doi.org/10.1037//0022-3514.82.3.448

van Bork, R., Rhemtulla, M., Waldorp, L. J., Kruis, J., Rezvanifar, S., \& Borsboom, D. (2019). Latent Variable Models and Networks: Statistical Equivalence and Testability. Multivariate Behavioral Research, 1-24. https://doi.org/10.1080/00273171.2019.1672515

Vancouver, J. B., Tamanini, K. B., \& Yoder, R. J. (2010). Using dynamic computational models to reconnect theory and research: Socialization by the proactive newcomer as example. Journal of Management, 36, 764-793. https://doi.org/10.1177/0149206308321550 
Vandenberg, R. J., \& Lance, C. E. (2000). A Review and Synthesis of the Measurement Invariance Literature: Suggestions, Practices, and Recommendations for Organizational Research. Organizational Research Methods, 3(1), 4-70. https://doi.org/10.1177/109442810031002

Verhelst, N. D., \& Glas, C. A. W. (1993). A dynamic generalization of the Rasch model. Psychometrika, 58(3), 395-415. https://doi.org/10.1007/BF02294648

Walton, R. D. (1936). Relations between amplitude of oscillations in short period efficiency and steadiness of character. British Journal of Psychology, XXVII.

Wang, C., Algozzine, B., Ma, W., \& Porfeli, E. (2011). Oral reading rates of second-grade students. Journal of Educational Psychology, 103(2), 442-454. https://doi.org/10.1037/a0023029

Wendt, L. P., Wright, A. G. C., Pilkonis, P. A., Woods, W. C., Denissen, J. J. A., Kühnel, A., \& Zimmermann, J. (2020). Indicators of affect dynamics: Structure, reliability, and personality correlates. European Journal of Personality, 34(6), 1060-1072. https://doi.org/10.1002/per.2277

Wille, B., \& De Fruyt, F. (2014). Vocations as a source of identity: Reciprocal relations between big five personality traits and RIASEC characteristics over 15 years. Journal of Applied Psychology, 99(2), 262-281. https://doi.org/10.1037/a0034917

World Bank. (2019). The changing nature of work (World Development Report). Author. http://documents.worldbank.org/curated/en/816281518818814423/pdf/2019-WDR-Report.pdf

Wouters, S., De Fraine, B., Colpin, H., Van Damme, J., \& Verschueren, K. (2012). The effect of track changes on the development of academic self-concept in high school: A dynamic test of the bigfish-little-pond effect. Journal of Educational Psychology, 104(3), 793-805. https://doi.org/10.1037/a0027732

Zhu, J., Wanberg, C. R., Harrison, D. A., \& Diehn, E. W. (2016). Ups and downs of the expatriate 
experience? Understanding work adjustment trajectories and career outcomes. Journal of Applied Psychology, 101(4), 549-568. https://doi.org/10.1037/apl0000073 
Table 1

Typology of Dynamic Work-Related Individual Differences Constructs

\begin{tabular}{|c|c|c|c|c|c|}
\hline $\begin{array}{l}\text { Dynamic } \\
\text { construct }\end{array}$ & Description & $\begin{array}{l}\text { Typical statistical model } \\
\text { specification (Bold represents the } \\
\text { individual difference construct and } \\
Y_{i j} \text { the behavior) }\end{array}$ & $\begin{array}{c}\text { Examples for } \\
\text { operationalizations and } \\
\text { measurement }\end{array}$ & $\begin{array}{l}\text { Examples for theoretical } \\
\text { concepts linked to the } \\
\text { conceptualization }\end{array}$ & Methodological techniques \\
\hline Variability & $\begin{array}{l}\text { Individual } \\
\text { differences in } \\
\text { inconsistency } \\
\text { across situations }\end{array}$ & $\begin{array}{c}\text { - } \quad \text { Level-1 (Measurements) } \\
-\quad Y_{\mathrm{ij}}=\pi_{0 \mathrm{j}}+\pi_{1 \mathrm{j}} T I M E_{\mathrm{i}} \\
+e_{\mathrm{ij}} \\
\text { - } \quad \text { Level-2 (Persons) } \\
-\quad \pi_{0 \mathrm{j}}=\gamma_{00}+u_{0 \mathrm{j}} \\
-\quad \pi_{1 \mathrm{j}}=\gamma_{10} \\
\text { - Residual part } \\
-\quad e_{\mathrm{ij}} \sim N(0, \\
\left.\sigma^{2} \exp \left[u_{7 \mathrm{j}}\right]\right)\end{array}$ & $\begin{array}{l}\text { Performance variability as } \\
\text { predictor of compensation } \\
\text { (Barnes et al. 2012); } \\
\text { variability in reactions to } \\
\text { situational judgement } \\
\text { items predicting } \\
\text { performance (Lievens at al., } \\
\text { 2018) }\end{array}$ & $\begin{array}{l}\text { Trait variability models, } \\
\text { work on within-person } \\
\text { fluctuations (e.g., Fleeson } \\
\text { \& Gallager, 2009). }\end{array}$ & $\begin{array}{l}\text { Distribution estimates like } \\
\text { the standard deviation and } \\
\text { the variance across time } \\
\text { within the person (Fleeson, } \\
\text { 2001); mixed-effects models } \\
\text { with variance functions } \\
\text { (Bolker, 2008; Pinheiro \& } \\
\text { Bates, 2000; Raudenbush, } \\
\text { 1988); mixed effect location } \\
\text { scale models (Rast, Hofer, et } \\
\text { al., 2012); Trait variability } \\
\text { IRT model (Lang, Lievens, et } \\
\text { al., 2019) }\end{array}$ \\
\hline $\begin{array}{l}\text { Skill } \\
\text { acquisition }\end{array}$ & $\begin{array}{l}\text { Individual } \\
\text { differences in } \\
\text { learning new } \\
\text { skills }\end{array}$ & $\begin{array}{l}\text { - Level-1 (Measurements) } \\
-\quad \gamma_{\mathrm{ij}}=\pi_{0 \mathrm{j}}+\pi_{1 \mathrm{j}} T I M E_{\mathrm{i}}+ \\
\pi_{2 \mathrm{j}} T_{I M E_{\mathrm{i}}^{2}+e_{\mathrm{ij}}} \\
\text { - Level-2 (Persons) } \\
-\quad \pi_{0 \mathrm{j}}=\gamma_{00}+u_{0 \mathrm{j}} \\
-\quad \pi_{1 \mathrm{j}}=\gamma_{10}+u_{1 \mathrm{j}}\end{array}$ & $\begin{array}{l}\text { Variability in the increase } \\
\text { of oral reading rates over } \\
\text { one school year (Wang et } \\
\text { al., 2011); predicting the } \\
\text { variability in the increase of } \\
\text { innovative behavior ( } \mathrm{Ng} \mathrm{\&}\end{array}$ & $\begin{array}{l}\text { Cognitive skill acquisition } \\
\text { (Ackerman, 1992); } \\
\text { Personality change (Wille } \\
\text { \& De Fruyt, 2014) }\end{array}$ & $\begin{array}{l}\text { Growth modeling (Bliese \& } \\
\text { Ployhart, 2002; Duncan et } \\
\text { al., 1999; Ployhart \& } \\
\text { Vandenberg, 2010) }\end{array}$ \\
\hline
\end{tabular}


$-\quad \pi_{2 j}=\gamma_{20}$

$\begin{array}{ll}\text { Transition } & \text { Individual } \\ & \text { differences in } \\ & \text { avoiding „loss“ } \\ & \text { after unforeseen } \\ & \text { change }\end{array}$

Reacquisition Individual

differences in

relearning after

change
- Level-1 (Measurements)

$-\quad Y_{\mathrm{ij}}=\pi_{0 \mathrm{j}}+\pi_{1 \mathrm{j}} T I M E_{\mathrm{i}}$ $+\pi_{2 \mathrm{j}} S A_{\mathrm{i}}{ }^{2}+\pi_{3 \mathrm{j}} T A_{\mathrm{i}}+$ $\pi_{4 j} R A_{i}+\pi_{5 j} R A_{i}^{2}+e_{i j}$

- Level-2 (Persons)

$-\pi_{0 j}=\gamma_{00}+u_{0 j}$

- $\pi_{1 j}=\gamma_{10}$

$-\quad \pi_{2 j}=\gamma_{20}$

$-\pi_{3 j}=\gamma_{30}+\mathbf{u}_{3 \mathbf{j}}$

$-\pi_{4 j}=\gamma_{40}$

$-\pi_{5 j}=\gamma_{50}$

- Level-1 (Measurements) Individual differences in

- $\quad Y_{i j}=\pi_{0 j}+\pi_{1 j} T I M E_{i} \quad$ performance adaption $+\pi_{2 \mathrm{j}} S A_{\mathrm{i}}{ }^{2}+\pi_{3 \mathrm{j}} T A_{\mathrm{i}}+\quad$ after change events (Howe,

$\pi_{4 j} R A_{\mathrm{i}}+\pi_{5 \mathrm{j}} R A_{\mathrm{i}}{ }^{2}+e_{\mathrm{ij}} \quad$ 2019); work adjustment in

- Level-2 (Persons)

$$
\begin{aligned}
& -\quad \pi_{0 j}=\gamma_{00}+u_{0 j} \\
& -\quad \pi_{1 j}=\gamma_{10} \\
& -\quad \pi_{2 j}=\nu_{20} \\
& -\quad \pi_{3 j}=\gamma_{30} \\
& -\quad \pi_{4 j}=\gamma_{40}+\mathbf{u}_{4 j} \\
& -\quad \pi_{5 j}=\gamma_{50}
\end{aligned}
$$

\begin{tabular}{|c|c|}
\hline $\begin{array}{l}\text { Self-image protection after } \\
\text { people engage unethical }\end{array}$ & $\begin{array}{l}\text { Theories on transition } \\
\text { processes and resilience }\end{array}$ \\
\hline behavior (Bonner et al., & (Bliese et al., 2017; \\
\hline 2017); Individual & Niessen \& Lang, 2020) \\
\hline
\end{tabular}

change in high school
Lucianetti, 2016)

differences in academic

self-concept after a track

(Wouters et al., 2012)

expatriates after relocation

(Zhu et al, 2016)

\section{Theories on transition \\ processes and resilience \\ (Bliese et al., 2017; \\ Niessen \& Lang, 2020)}

Discontinuous growth

models (Bliese et al., 2017;

Bliese \& Lang, 2016; Singer \& Willett, 2003); generalized estimating equation (LePine et al., 2000)

Discontinuous growth models (Bliese et al., 2017; Bliese \& Lang, 2016; Singer \& Willett, 2003); Growth models (Chen, 2005) 


$\begin{array}{ll}\text { Acceleration/ } & \text { Individual } \\ \text { deceleration } & \text { differences in } \\ & \text { losing energy by } \\ & \text { displaying the } \\ \text { behavior } & \text { (consummatory } \\ & \text { strengths) } \\ & \\ & \\ \text { Integration/ } & \\ \text { dissolution } & \begin{array}{l}\text { Individual } \\ \text { differences in } \\ \text { behavior } \\ \text { becoming more } \\ \text { or less uniform } \\ \text { over time }\end{array} \\ & \end{array}$

- Level-1 (Measurements)

- $\quad Y_{\mathrm{ij}}=\pi_{0 \mathrm{j}}+\pi_{1 \mathrm{j}} T I M E_{\mathrm{i}}$ $+\pi_{6 \mathrm{j}} C S_{\mathrm{i}}+e_{\mathrm{ij}}$

- $\quad$ where $C S_{\mathrm{i}}=C S_{\mathrm{i}-1}+$ $Y_{\mathrm{i}-1 \mathrm{j}}$ when $Y_{\mathrm{i}-1 \mathrm{j}}>$ cutoff (increases from $0,1,2,3$, etc. with $\pi_{6 j}$ typically being negative)

- Level-2 (Persons)

$$
\begin{array}{ll}
- & \pi_{0 j}=\nu_{00}+u_{0 j} \\
- & \pi_{1 j}=\nu_{10}+u_{1 j} \\
- & \pi_{6 j}=\nu_{60}+u_{6 j}
\end{array}
$$

- Level-1 (Measurements)

- $\quad Y_{\mathrm{ij}}=\pi_{0 \mathrm{j}}+\pi_{1 \mathrm{j}} T I M E_{\mathrm{i}}$

$$
+e_{\mathrm{ij}}
$$

- Level-2 (Persons)

$-\quad \pi_{0 j}=\nu_{00}+u_{0 j}$

$-\pi_{1 j}=\gamma_{10}$

- Residual part

$-\quad e_{\mathrm{ij}} \sim N(0$ $\sigma^{2} \exp \left[2 u_{8 \mathrm{j}} T I M E_{\mathrm{i}}\right]$

or
Dynamic system theories and models (Atkinson \& Birch, 1970; Carver \& Scheier, 1998; Lang, 2014; Revelle \& Michaels, 1976; Sosnowska, Hofmans, et al., 2019) (Chawla, 2016)

\section{Changes in individual level} knowledge processes result in changes in team-level cognition (Grand et al., 2016); dynamic leadership emergence in a team creativity and innovation setting (S.M. Lee and Farh, 2019)
Cognitive change in higher age (Rast, MacDonald, et al., 2012), resilience research (Gucciardi et al., 2018); research on ability integration/personality trait integration
Simulations, autocorrelation models (Bolker, 2008),

mixed-effects models, panel models, dynamic IRT models (Lang, 2014; Verhelst \& Glas, 1993), dynamic SEM models (Asparouhov et al., 2018)

\section{Mixed-effects models with} variance functions (Bolker 2008; Pinheiro \& Bates, 2000; Raudenbush, 1988),

\section{consensus emergence} model (Lang, Bliese, \& Adler, 2019); location scale models with a time variable (Hedeker et al., 2008), longitudinal network models 
$-e_{\mathrm{ij}} \sim N(0$,

$\sigma^{2} \exp \left[2\left(\delta_{1}+\right.\right.$

$\left.\left.u_{8 \mathrm{j}}\right) T\left(M E_{\mathrm{i}}\right]\right)$
(Miers et al., 2020; Niezink et al., 2019) 
Table 2

Model Estimates for Simulated Datasets Generated on the Dynamic Individual Differences Models in the Typology

\begin{tabular}{|c|c|c|c|c|c|c|}
\hline Parameters & Variability & $\begin{array}{c}\text { Skill } \\
\text { acquisition }\end{array}$ & Transition & Reacquisition & $\begin{array}{l}\text { Acceleration/ } \\
\text { Deceleration }\end{array}$ & $\begin{array}{l}\text { Integration/ } \\
\text { Dissolution }\end{array}$ \\
\hline Intercept, yoo & 3.00 & 3.02 & 2.98 & 3.03 & 3.00 & 2.98 \\
\hline TIME, $\gamma_{10}$ & 0.05 & 0.05 & 0.31 & 0.26 & 0.08 & 0.10 \\
\hline$S A 2^{2}, \gamma_{20}$ & & & -0.04 & -0.03 & & \\
\hline$T A, \gamma_{30}$ & & & -1.01 & -1.04 & & \\
\hline$R A, \gamma_{40}$ & & & -0.21 & -0.18 & & \\
\hline$R A^{2}, \gamma_{50}$ & & & 0.01 & 0.003 & & \\
\hline$C S, \gamma_{60}$ & & & & & -0.47 & \\
\hline Intercept variance, uo & 0.10 & 0.05 & 0.03 & 0.02 & 0.08 & 0.03 \\
\hline TIME variance, $\mathrm{U}_{1}$ & & 0.10 & & & 0.001 & \\
\hline$T A$ variance, $\mathrm{U}_{3}$ & & & 0.10 & & & \\
\hline$R A$ variance, $\mathrm{U}_{4}$ & & & & 0.10 & & \\
\hline$C S$ variance, $\mathrm{U}_{6}$ & & & & & 0.11 & \\
\hline Residual variance, $\sigma^{2}$ & 1.42 & 0.51 & 0.04 & 0.05 & 0.10 & 0.56 \\
\hline Intercepts, $u_{7 j}$ & $0.14 \ldots . . .61$ & & & & & \\
\hline TIME effects, $u_{8 j}$ & & & & & & $-0.77 \ldots-0.01$ \\
\hline $\log L i k$ & $-1,051.06$ & $-1,304.48$ & -75.14 & -217.06 & -577.47 & 150.87 \\
\hline$d f$ & 103 & 6 & 10 & 10 & 10 & 104 \\
\hline$R_{L R}^{2}$ & .37 & .78 & .77 & .83 & .75 & .84 \\
\hline
\end{tabular}

Note. For all datasets, $N=100$ with $k=1000$ observations. All models were fitted using the nlme package in R. The residual variance of the variability model refers to one case that is centered at 1 and each of the 100 cases has its own variability effect $u_{7 \mathrm{j}}$ defined relative to the index case. The integration/dissolution model also has a specific TIME effect for each person. In both cases, we only provide the range of these values to save space but the full values are available in the supplementary material. 
Table 3

Articles on Dynamic Individual Differences Published Between 2005 and 2020 By the Type of Dynamic Individual

Difference and Journal

\begin{tabular}{|c|c|c|c|c|c|}
\hline \multirow[b]{3}{*}{ Category } & \multirow{3}{*}{$\begin{array}{l}\text { Journal of } \\
\text { Applied } \\
\text { Psychology }\end{array}$} & \multirow{3}{*}{$\begin{array}{l}\text { Personnel } \\
\text { Psychology }\end{array}$} & & \multirow{3}{*}{$\begin{array}{l}\text { Journal of } \\
\text { Educational } \\
\text { Psychology }\end{array}$} & \multirow[b]{3}{*}{ Total } \\
\hline & & & \multirow{2}{*}{$\begin{array}{l}\text { Human } \\
\text { Performance }\end{array}$} & & \\
\hline & & & & & \\
\hline \multicolumn{6}{|c|}{ Included articles } \\
\hline Main effects labelled as dynamic & 10 & 2 & 1 & 8 & 21 \\
\hline Mentioned in the literature & 14 & 5 & 1 & 9 & 29 \\
\hline Normative dynamics & 52 & 7 & 5 & 22 & 86 \\
\hline $\begin{array}{l}\text { Questionnaire asking for dynamic } \\
\text { individual differences }\end{array}$ & 8 & 2 & 3 & 2 & 15 \\
\hline Dynamic individual differences & 50 & 7 & 3 & 16 & 76 \\
\hline Total & 134 & 23 & 13 & 57 & 227 \\
\hline \multicolumn{6}{|c|}{ Types of individual differences in dynamics } \\
\hline Variability & 22 & 3 & 1 & 3 & 29 \\
\hline Skill acquisition & 20 & 2 & 2 & 12 & 36 \\
\hline Transition & 6 & 1 & 0 & 1 & 9 \\
\hline Reacquisition & 6 & 1 & 0 & 0 & 7 \\
\hline Acceleration/Deceleration & 4 & 1 & 0 & 0 & 5 \\
\hline Integration/Dissolution & 4 & 1 & 0 & 0 & 5 \\
\hline Total & 62 & 9 & 3 & 16 & 90 \\
\hline
\end{tabular}

Note. The number of codings for the dynamic individual differences categories $(n=90)$ exceed the total number of articles including dynamic individual differences $(n=76)$, because 14 articles studied two dynamic individual differences categories. 
Table 4

Articles on Dynamic Individual Differences Published Between 2005 and 2020 By the Type of Dynamic Individual Difference and the Research Focus with Journal in Parentheses (Journal of Applied Psychology/Personnel Psychology/Human Performance/Journal of Educational Psychology)

\begin{tabular}{lrrrr}
\hline \multicolumn{1}{c}{ Dynamic individual difference } & \multicolumn{1}{c}{$\begin{array}{c}\text { Dynamic } \\
\text { assessment }\end{array}$} & \multicolumn{1}{c}{$\begin{array}{l}\text { Dynamic } \\
\text { criterion }\end{array}$} & $\begin{array}{c}\text { Dynamic assessment } \\
\text { and criterion }\end{array}$ & \multicolumn{1}{c}{ Total } \\
\hline Variability & $9(9 / 0 / 0 / 0)$ & $15(10 / 2 / 2 / 1)$ & $5(3 / 1 / 0 / 1)$ & 29 \\
Skill acquisition & $9(4 / 0 / 4 / 1)$ & $22(12 / 1 / 1 / 8)$ & $5(4 / 1 / 0 / 0)$ & 36 \\
Transition & $1(1 / 0 / 0 / 0)$ & $7(5 / 1 / 0 / 1)$ & 0 & 8 \\
Reacquisition & 0 & $7(6 / 1 / 0 / 0)$ & 0 & 7 \\
Acceleration/deceleration & 0 & $5(4 / 1 / 0 / 0)$ & 0 & 5 \\
Integration/dissolution & 0 & $5(4 / 1 / 0 / 0)$ & 0 & 5 \\
\hline Total & $19(14 / 0 / 4 / 1)$ & $61(41 / 7 / 3 / 10)$ & $10(7 / 2 / 0 / 1)$ & 90
\end{tabular}

Note. The total number of the articles is lower than the combined total of the six categories because 14 articles included more than one dynamic individual differences categories. 
Table 5

Articles on Dynamic Individual Differences Published Between 2005 and 2020 By the Type of Dynamic and years

\begin{tabular}{|c|c|c|c|}
\hline Category & $2005-2009$ & $2010-2014$ & $2015-2020$ \\
\hline \multicolumn{4}{|c|}{ Included Articles } \\
\hline Main effects labelled as dynamic & 5 & 8 & 7 \\
\hline Mentioned in the literature & 10 & 8 & 12 \\
\hline Normative dynamics & 21 & 28 & 37 \\
\hline \multicolumn{4}{|l|}{ Questionnaire asking for dynamic } \\
\hline individual differences & 5 & 7 & 3 \\
\hline Dynamic individual differences & 16 & 28 & 32 \\
\hline Total & 57 & 79 & 91 \\
\hline \multicolumn{4}{|c|}{ Types of individual differences in dynamics } \\
\hline Variability & 4 & 9 & 16 \\
\hline Skill acquisition & 9 & 18 & 9 \\
\hline Transition & 2 & 2 & 4 \\
\hline Reacquisition & 2 & 1 & 4 \\
\hline Acceleration/Deceleration & 1 & 1 & 3 \\
\hline Integration/Dissolution & 0 & 2 & 3 \\
\hline Total & 18 & 33 & 39 \\
\hline
\end{tabular}

Note. The number of codings for the dynamic individual differences categories $(n=90)$ exceed the total number of articles including dynamic individual differences $(n=76)$, because 14 articles studied two dynamic individual differences categories. 
Table 6

$R_{L R}^{2}$ For Fitting the Correct and the Wrong Models To the Simulated Datasets

\begin{tabular}{|c|c|c|c|c|c|c|}
\hline \multirow[b]{2}{*}{ Model } & \multicolumn{6}{|c|}{ Dataset } \\
\hline & Variability & $\begin{array}{l}\text { Skill } \\
\text { acquisition }\end{array}$ & Transition & Reacquisition & $\begin{array}{l}\text { Acceleration/ } \\
\text { Deceleration }\end{array}$ & $\begin{array}{l}\text { Integration/ } \\
\text { Dissolution }\end{array}$ \\
\hline Variability & .37 & .61 & .33 & .39 & .61 & .58 \\
\hline Skill acquisition & .06 & .78 & .30 & .46 & .59 & .43 \\
\hline Transition & .06 & .70 & .77 & .60 & .61 & .41 \\
\hline Reacquisition & .06 & .69 & .72 & .83 & .59 & .41 \\
\hline Acceleration/ & NC & NC & NC & NC & .75 & $\mathrm{NC}$ \\
\hline Deceleration & & & & & & \\
\hline Integration/ & .32 & .64 & .36 & .51 & .60 & .84 \\
\hline Dissolution & & & & & & \\
\hline
\end{tabular}

Note. $\mathrm{NC}=$ nonconvergence. 
Figure 1. Simulated data illustrating individual differences in a variability construct. The solid line in the two panels is the sample average across the whole sample. The left and right panel only include individuals with high and low levels of the variability construct, respectively (median split).

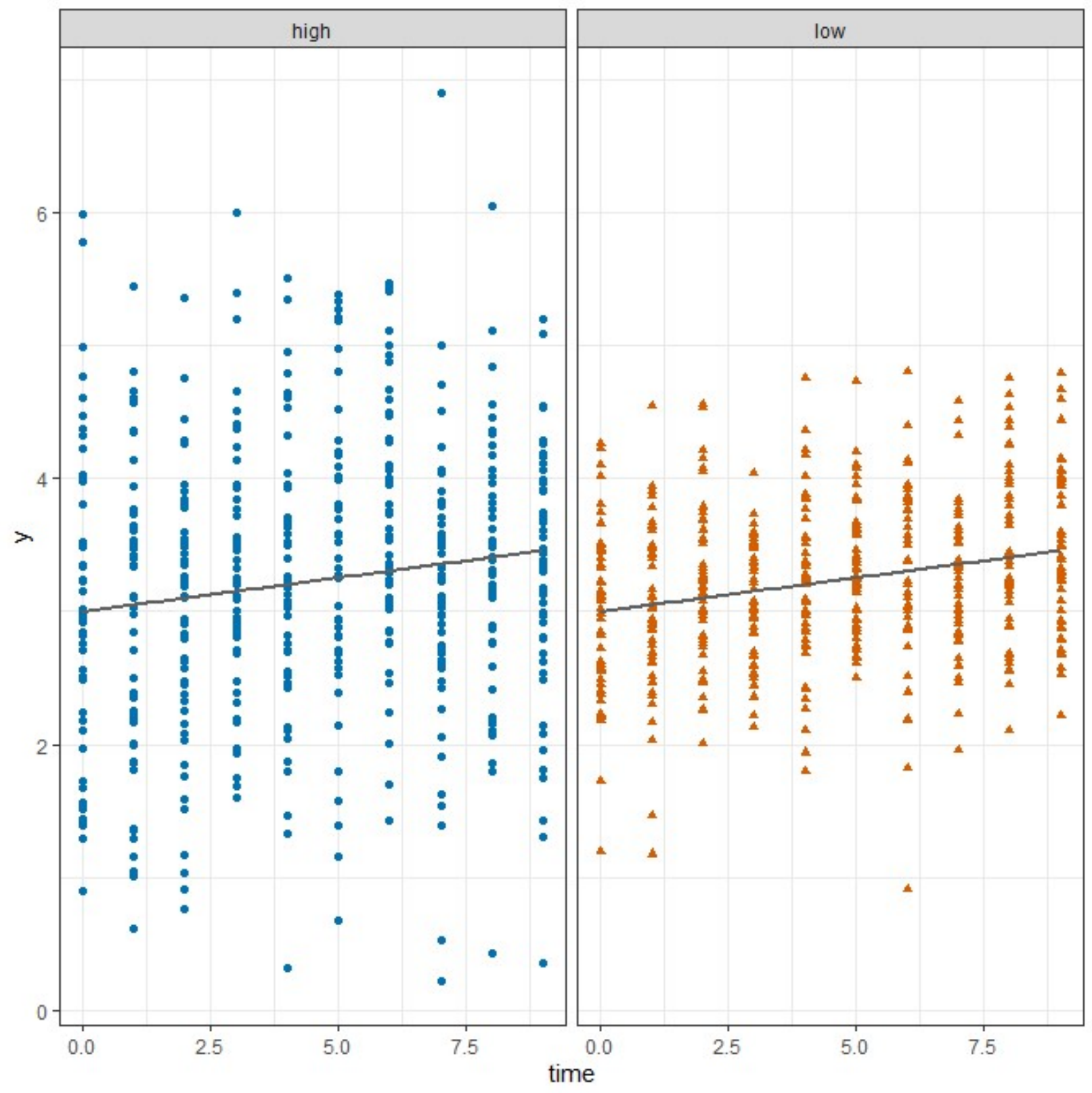


Figure 2. Simulated data illustrating individual differences in a skill acquisition construct. The solid line in the two panels is the sample average across the whole sample. The left and right panel only include individuals with high and low levels of the skill acquisition construct, respectively (median split).

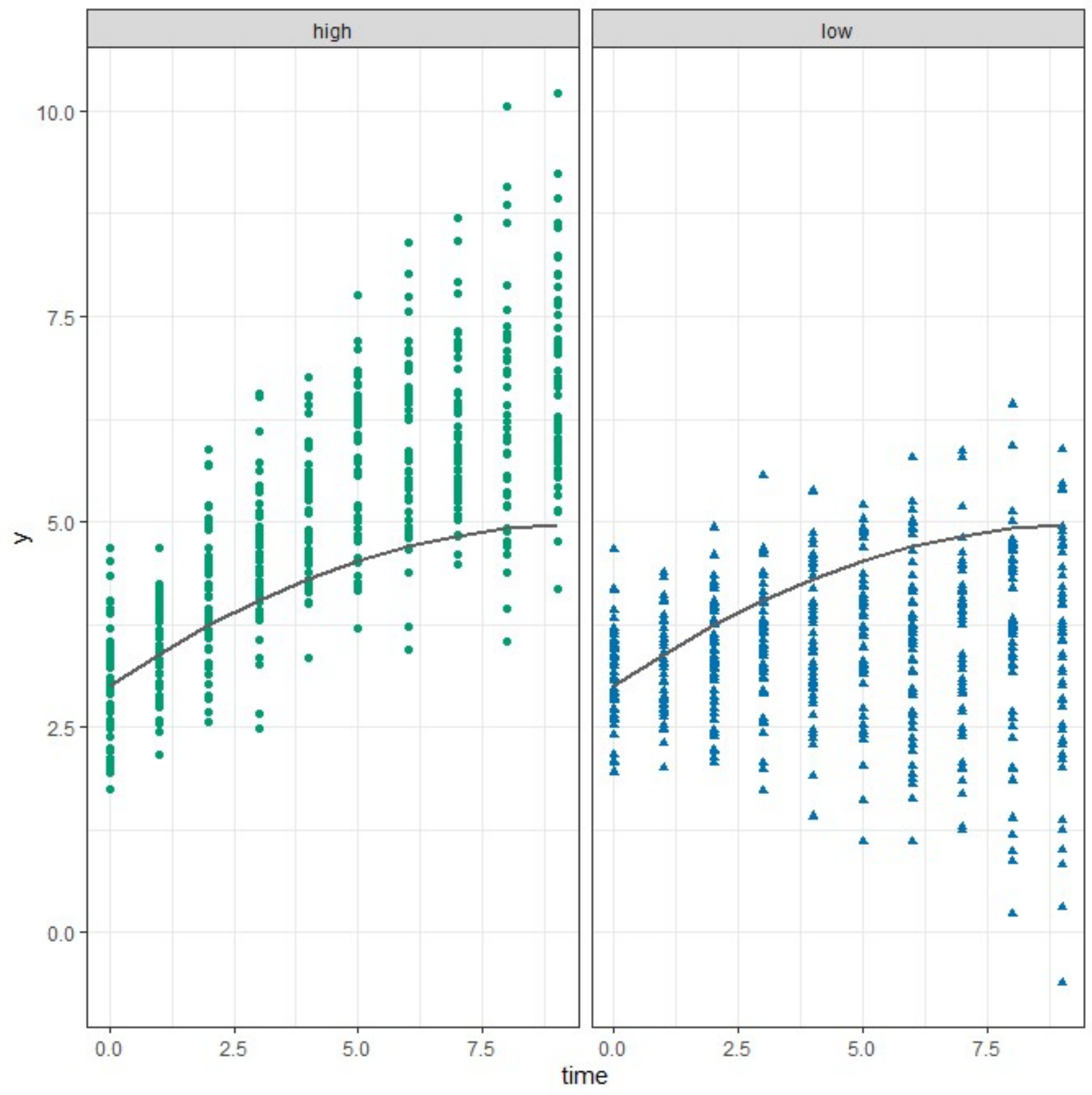


Figure 3. Simulated data illustrating individual differences in a transition construct. The solid line in the two panels is the sample average across the whole sample. The left and right panel only include individuals with high and low levels of the transition construct, respectively (median split). As shown in the graph, individuals with high levels in the transition construct have higher performance after the change.

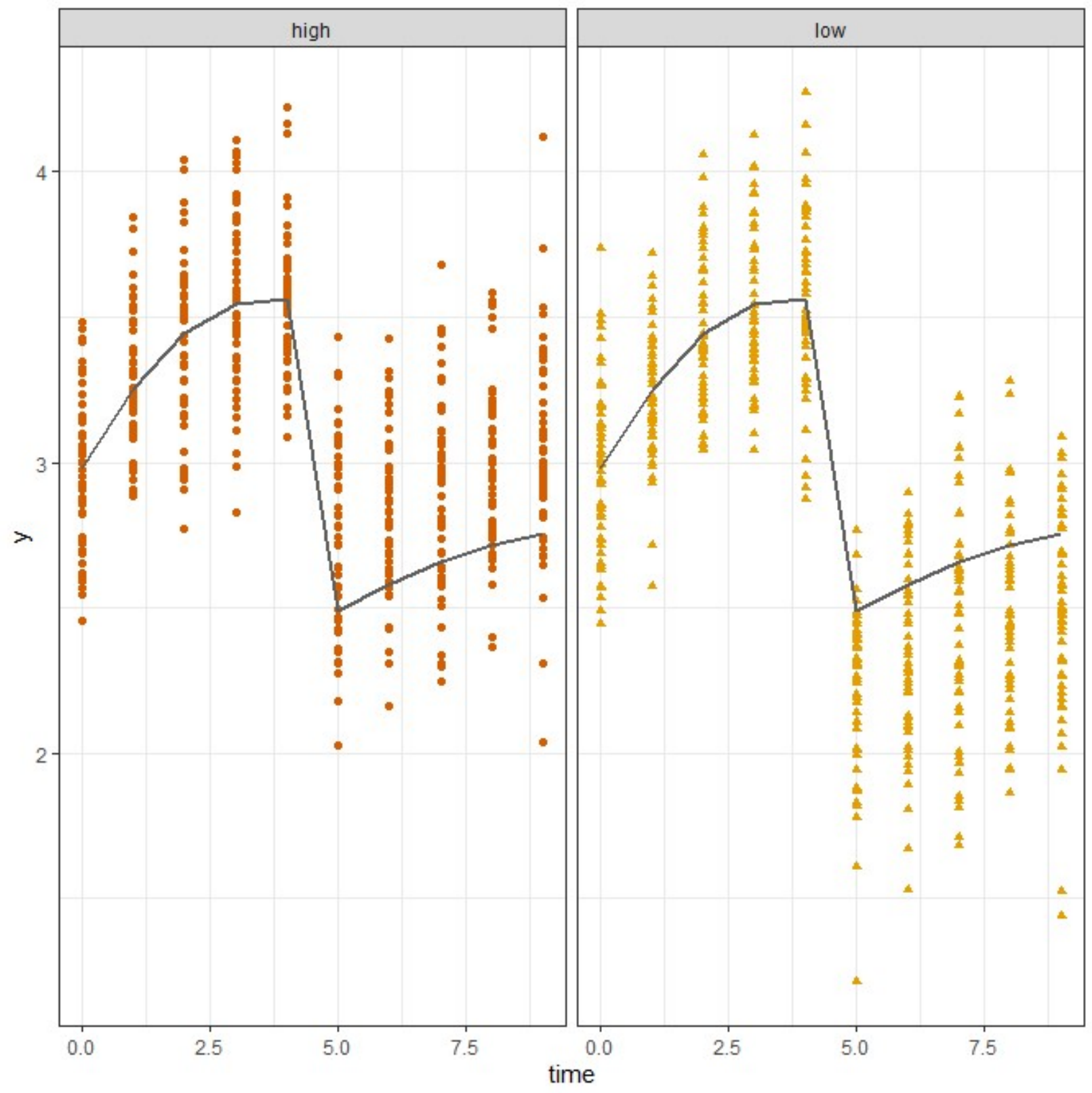


Figure 4. Simulated data illustrating individual differences in a reacquisition construct. The solid line in the two panels is the sample average across the whole sample. The left and right panel only include individuals with high and low levels of the reacquisition construct, respectively (median split). As shown in the graph, individuals with high levels in the reacquisition construct are quicker in gradually relearning/adapting to the situation after the change.
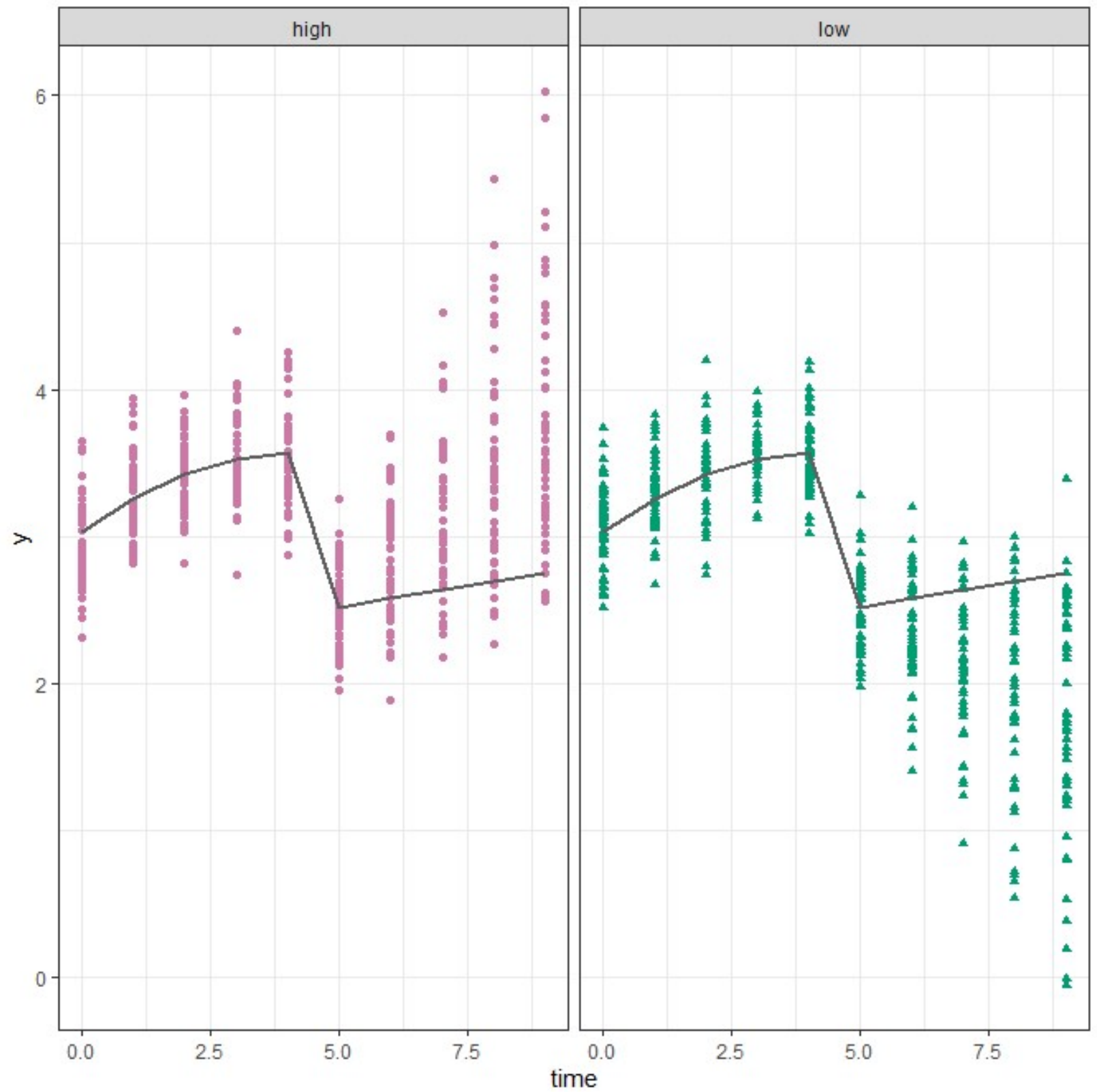
Figure 5. Simulated data illustrating individual differences in a acceleration/deceleration construct. The solid line in the two panels is the sample average across the whole sample. The left and right panel only include individuals with high and low levels of the acceleration/deceleration construct, respectively (median split). The graph shows that individuals with high levels in the acceleration/deceleration construct have a stable pattern where increases in the behavior are countered by subsequent dynamic decreases. In contrast, low levels of the construct in the example allow individuals to show quite substantive increases (see the right panel).
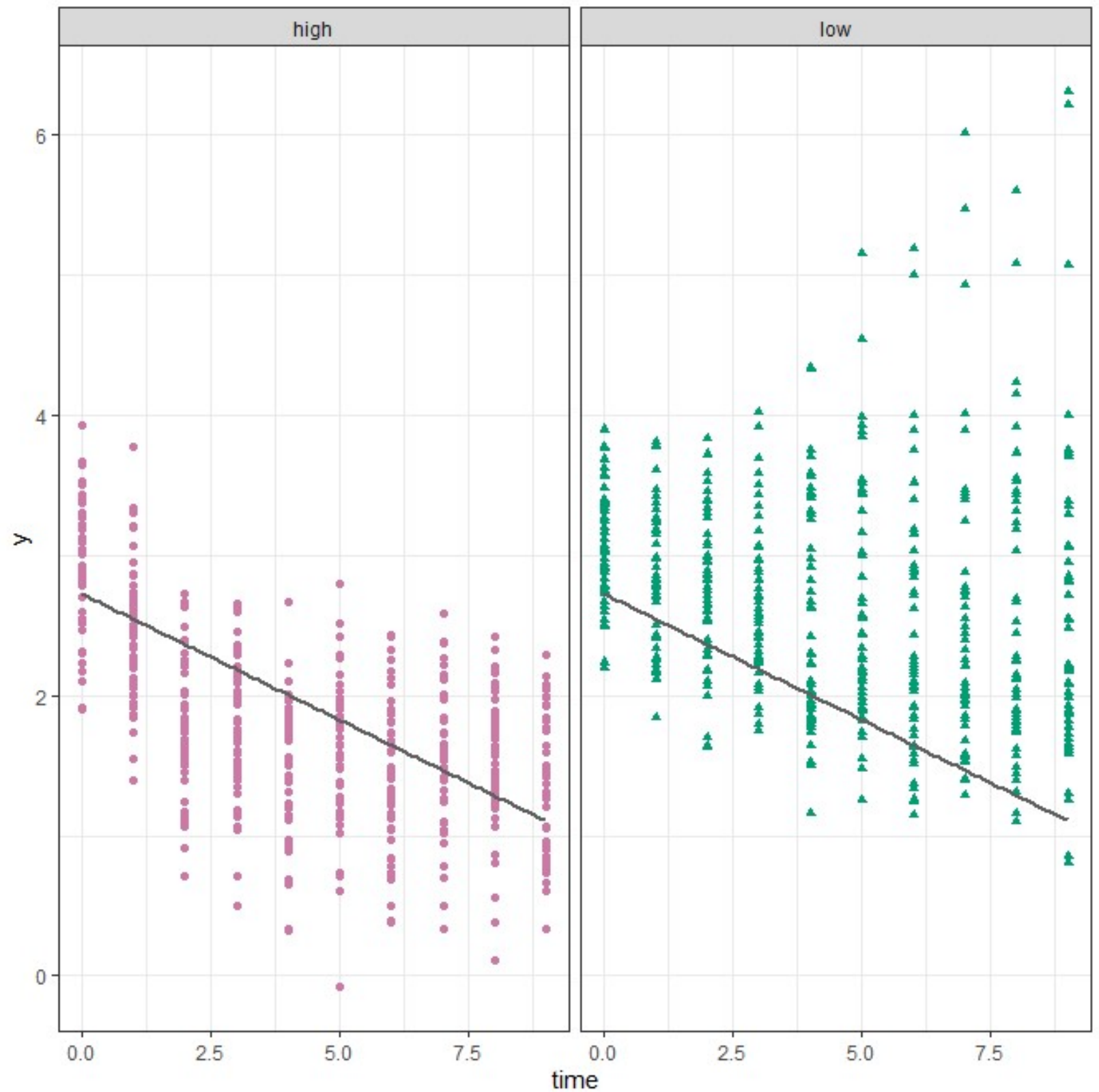
Figure 6. Simulated data illustrating individual differences in a dissolution/integration construct. The solid line in the two panels is the sample average across the whole sample. The left and right panel only include individuals with high and low levels of the skill acquisition construct, respectively (median split). As shown in the graph, individuals with high levels of the construct show increasingly more consistent behavior over time. In contrast, individuals with low levels in the construct continue to show relatively more inconsistent behavior.
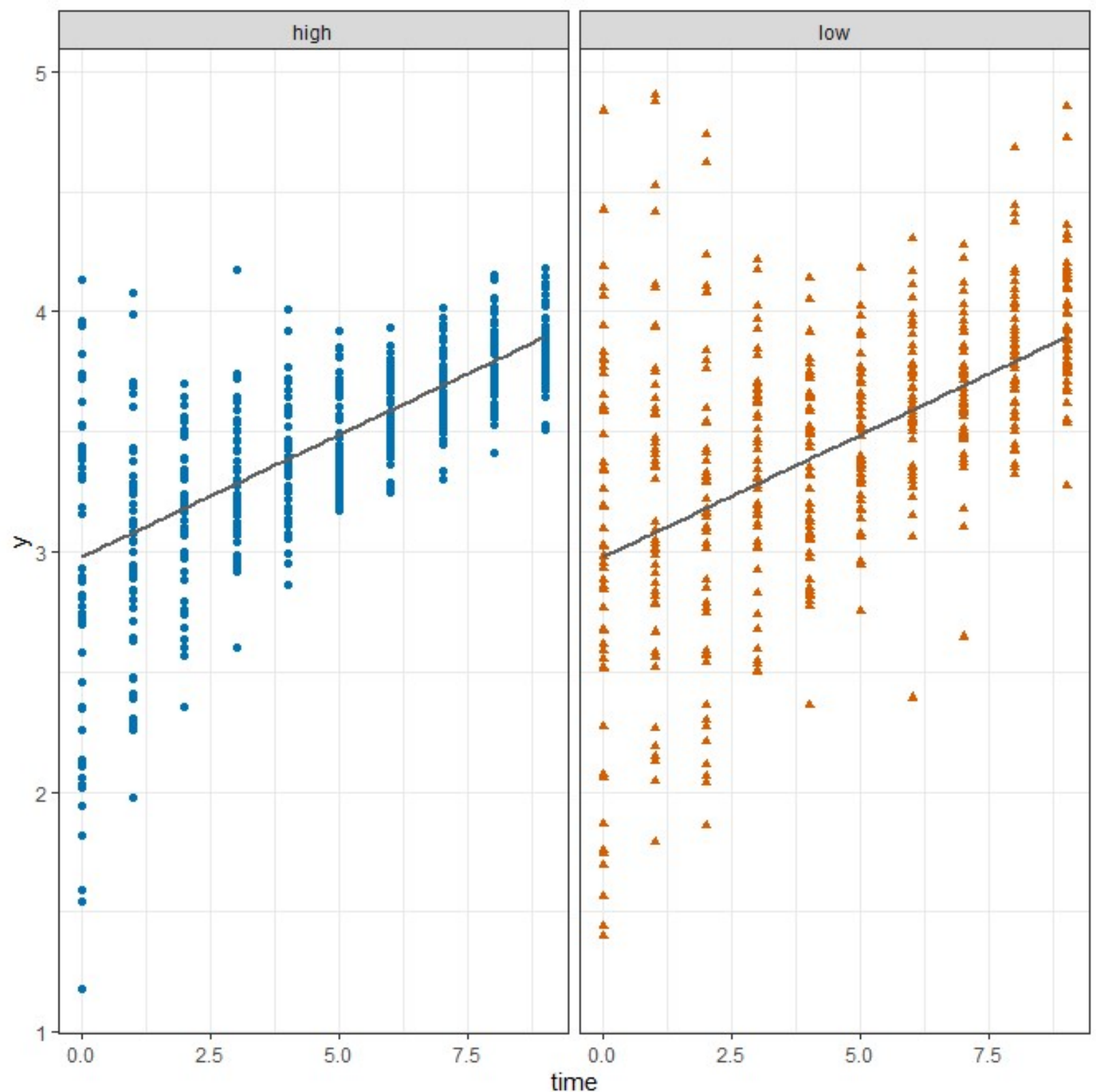
Figure 7. Flow chart describing the identification, screening, eligibility assessment, and final inclusion for the literature study.

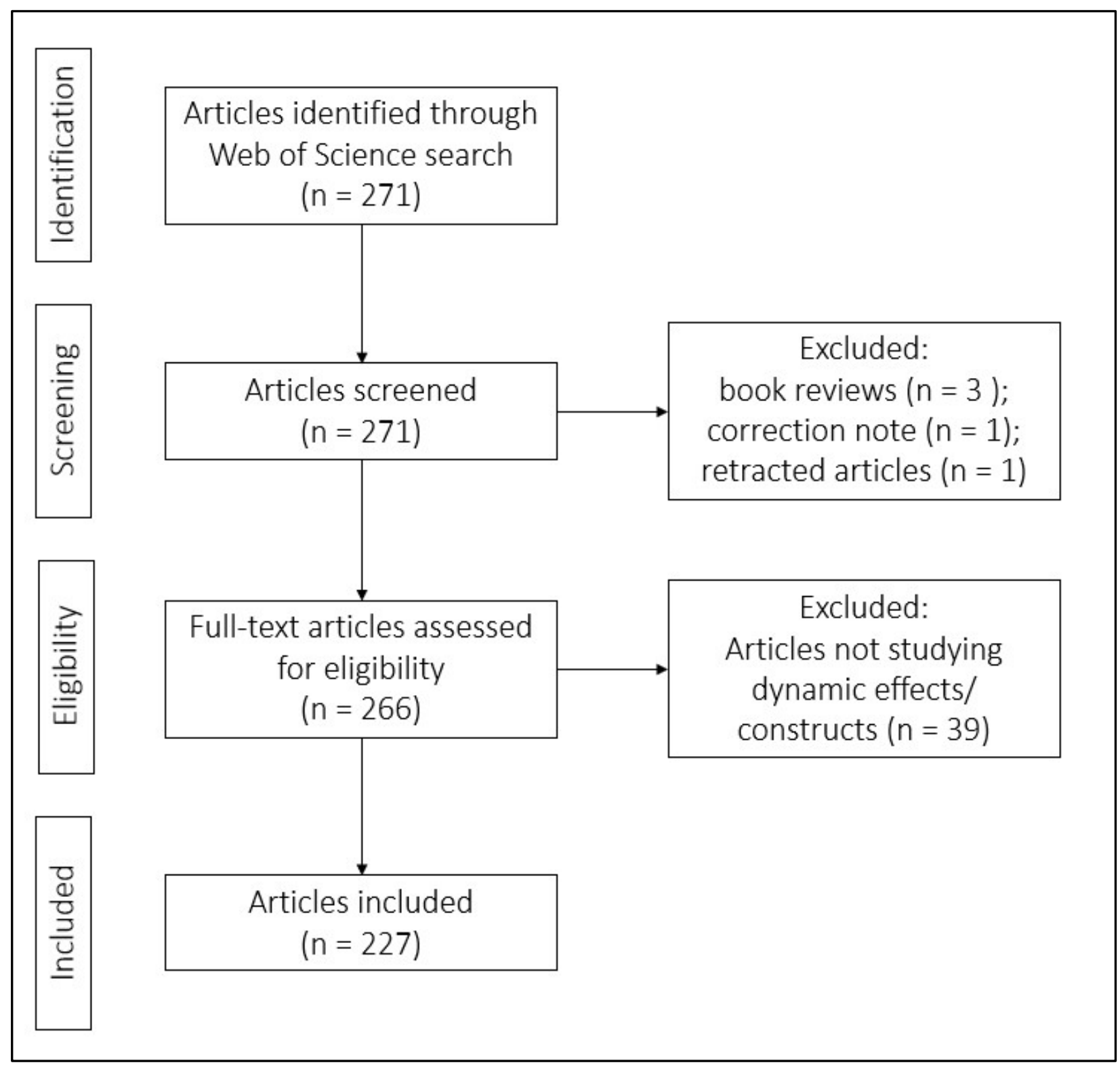

